\title{
EL RÉGIMEN JURÍDICO DE LA OCUPACIÓN A LA LUZ DE ALGUNOS CASOS RECIENTES, ESPECIALMENTE EL DE LA FRANJA DE GAZA
}

\author{
Romualdo Bermejo ${ }^{1}$, Eugenia López-Jacoiste ${ }^{2}$ \\ Instituto Universitario "General Gutiérrez Mellado"/ Universidad de Leon/ \\ Universidad de Navarra
}

\begin{abstract}
:
Este estudio analiza el régimen de ocupación en la actualidad, sobre todo en aquellos casos de longa manu como son los territorios palestinos, aunque también existan otras situaciones confusas. El actual régimen jurídico internacional de ocupación debería adaptarse a las nuevas circunstancias presentes en la sociedad internacional actual, enriqueciéndolo con un nuevo cuerpo de normas que aclaren determinadas situaciones confusas, como es el caso de la Franja de Gaza. Cuando no hay boots on the ground, como es el caso de la Franja de Gaza, para que se pueda considerar ocupado un territorio, tienen que darse unas condiciones que puedan permitir controlar y ejercer de facto como Potencia ocupante, sin que esto suponga operaciones bélicas de gran envergadura que de facto equivaldría a una "nueva reocupación".
\end{abstract}

Palabras Clave: Ocupación, control de efectividad territorios palestinos ocupados, Franja de Gaza, Derecho internacional humanitario, derechos humanos, decisiones de la Corte

Title in English: The legal regime of occupation in the light of some recent cases, specially that of the Gaza strip

\section{Resumen:}

This study analyzes the occupation regime at the present time, especially in those cases of longa manu as in the Palestinian territories, although there are other confusing situations too. The current international legal regime of occupation should be adapted to the new circumstances of the current international society. The legal framework should be enriched with a new body of rules that clarify certain situations that, in the light of current international law, are confusing, as for example, Iraq and the Gaza Strip. If there are no boots on the ground - as in the Gaza Strip - occupation requires very special conditions to exercise de facto control as an occupying Power, without involving military operations that would be de facto a "new reoccupation".

Key Words: Occupation, effective control test, occupied Palestinian territories, Gaza Strip, International humanitarian law, human rights, Court's decisions

Copyright @ C UNISCI, 2019.

Las opiniones expresadas en estos artículos son propias de sus autores, y no reflejan necesariamente la opinion de UNISCI. The views expressed in these articles are those of the authors, and do not necessarily reflect the views of UNISCI.

\footnotetext{
${ }^{1}$ Romualdo Bermejo. Catedrático de Derecho Internacional Público, Universidad de Leon. Profesor del Instituto Universitario "General Gutiérrez Mellado"

E-mail: <rberg@unileon.es>

${ }^{2}$ Eugenia López -Jacoiste. Profesora Titular de Derecho Internacional Público, Universidad de Navarra

E-mail<ejacoiste@unav.es>

DOI: http://dx.doi.org/10.31439/UNISCI-65
} 


\section{Introduction}

Al margen de las consideraciones generales que haremos en relación con los denominados territorios ocupados por Israel, consideraciones que, a la hora de aplicarlas a la compleja situación de estos territorios, no dejan de plantear ciertas dudas a la luz del Derecho internacional humanitario vigente, al menos desde el punto de vista convencional, la cuestión que surge de forma despiadada es saber cómo calificar ahora la situación en $\mathrm{Gaza}^{3}$ tras las retirada completa de las fuerzas israelíes de este territorio en 2005, así como de los ocho mil colonos que se encontraban en los asentamientos. Es decir, dentro de Gaza no hay ninguna presencia ni civil ni militar de Israel. Esta nueva situación trae consigo que se revela muy difícil seguir considerando a Israel como Potencia Ocupante sobre este territorio a la luz del Derecho internacional humanitario, como veremos a continuación.

En efecto, el derecho que regula la Ocupación fue codificado inicialmente en el Reglamento de la Haya del 18 de octubre de 1907, cuyo artículo 42 señala de una forma precisa que "Se considera como ocupado un territorio cuando se encuentra colocado de hecho bajo la autoridad del ejército enemigo. La ocupación no se extiende sino a los territorios donde esa autoridad está establecida y en condiciones de ejercerse". Como se puede comprobar, este texto se refiere sobre todo a la autoridad militar de la Potencia Ocupante sobre el territorio del Estado enemigo, es decir, que se encuentra ocupado. Y es que como señalan Robert Kolb y Sylvain Vité, la óptica que está presente en esta Convención no es precisamente la situación del individuo sometido al poder de la Potencia Ocupante, sino que de lo que se trata es de una relación de Estado a Estado, es decir entre la Potencia Ocupante y el territorio del Estado ocupado. Esto lo muestra con claridad el hecho de que las dos posiciones relativas de las personas son mínimas, tanto cualitativamente como cuantitativamente ${ }^{4}$, y están relacionadas con la familia (artículo 46) o con la población del territorio ocupado en general, aunque a través de este concepto de población, al destinatario directo va a ser el individuo. No hay que perder de vista que cuando se adopta este Reglamento, los mecanismos internacionales relativos a la protección de los derechos humanos eran todavía muy escasos, sobre todo en relación con los que tenemos en la actualidad 5 .

Las lagunas en esta materia que se pueden vislumbrar en el Reglamento de la Haya serían colmadas después por los Convenios de Ginebra de 12 de agosto de 1949, con la voluntad de reforzar y de asegurar la protección de las víctimas de la guerra al imponer un amplio abanico de normas a las Potencias Ocupantes con el fin de garantizar tanto el Derecho internacional humanitario stricto sensu como el de los derechos humanos, ambos muy interrelacionados ${ }^{6}$. Hay que recalcar, sin embargo, que esta protección se encuentra sobre todo desarrollada en el Cuarto Convenio de Ginebra, algo que se deduce ya del propio título que versa sobre "la

\footnotetext{
${ }^{3}$ En este trabajo utilizamos Gaza o Franja de Gaza para referirnos a este territorio.

${ }^{4}$ Kolb, Robert y Vité, Silvain : "L'applicabilité ratione temporis du droit de l'occupation de guerre: le debut et la fin de l'occupation", en Chetail, Vicent. (ed.) (2013) : Permanence et mutations du droit des conflits armés, Bruylant, Bruselas, pp. 116 y ss.

${ }^{5}$ Para más detalles, Benvenisti, Eyal (2012) : The International Law of Occupation, Oxford University Press, Oxford, $2^{a}$ ed. 416 p. Para unos comentarios muy interesantes a esta obra imprescindible en materia de ocupación de territorios, véase. Fox, Gregory. H : "Eyal Benvenisti. The International Law of occupation”, European Journal of International Law, vol. 24, $\mathrm{n}^{\circ} 1$ (February 2013).

${ }^{6}$ Para un estudio sobre la interrelación entre estos dos sistemas jurídicos de protección, véase entre otros muchos, Arai-Takashi, Yutuka (2009).: The Law of Ocupation: Continuity and Change of International Humanitarian Law, and its Interactions with International Human Rights, Nijhoff, Leiden, 760 p.; Ghelali, Anna.: "Lex specialis, droit international humanitaire et droits de l'homme: leur interaction dans les nouveaux conflits armés”, RGDIP (2007), pp. 539-574 ; Ferraro, Tristan: "The Law of Occupation and Human Rights Law: some Selected Issues", en: Gaggioli, Gloria. y Kolb, Robert (eds.) (2014): Research Handbook on Human Rights and Humanitarian Law. Edward Elgar, Cheltenham, 704 p.y Lubell, Noam.: "Human Rights Obligations in Military Occupation", Int. Rev. Red. Cross (2012), pp. 317-337.
} 
protección debida a las personas civiles en tiempo de guerra”, de 12 de agosto de 1949. Sin embargo, no todos los individuos tienen protección en virtud de este Convenio, pues como señala el artículo 4, párrafo 1 "El presente Convenio protege a las personas que, en cualquier momento y de la manera que sea, estén, en caso de conflicto o de ocupación, en poder de una parte en conflicto o de una Potencia ocupante de la cual no sean súbditas". No obstante, el Convenio tiene también disposiciones de protección general que se aplican a cualquier persona que se encuentre en una Parte contratante en conflicto al margen de su nacionalidad, como el artículo 3, y los artículos 13-26 del Título II, cuyo título es "Protección general de la población contra ciertos efectos de la guerra". Este marco de protección se encuentra además reforzado por el Protocolo I adicional a los Convenios de Ginebra del 8 de junio de 1977, aunque Israel no es Parte en él, por lo que solo se aplicarían las normas consuetudinarias. Hechas estas consideraciones, y a la luz de la retirada de las fuerzas armadas israelíes del territorio de Gaza, tal y como ya hemos visto ¿Se puede considerar hoy en día que Gaza es un territorio ocupado?

\section{La definición de la Ocupación y su alcance}

Tal y como reza el artículo 2, párrafo 2 común a los cuatro Convenios de Ginebra, "el Convenio se aplicará también en todos los casos de ocupación total o parcial del territorio de una de una Alta Parte Contratante, aunque tal ocupación no encuentre resistencia militar". Al tratarse, pues, de un conflicto armado internacional, el régimen de ocupación va a estar regulado por el ius in bello, es decir no solo por los Convenios de Ginebra, especialmente el cuarto Convenio relativo a la protección debida a las personas civiles en tiempo de guerra, sino también por el ya citado Reglamento de La Haya de 1907 y por el Protocolo I de 1977.

Desde esta perspectiva, el primer instrumento jurídico que define y delimita el régimen de la ocupación es el Reglamento de La Haya, en cuyo artículo 42 se señala que "Se considera como ocupado un territorio cuando se encuentra colocado de hecho bajo la autoridad del ejército enemigo". Es más, el párrafo 2 de dicha disposición lo refuerza al precisa que "La ocupación no se extiende sino a los territorios donde esa autoridad esté y en condiciones de ejercerse". Ninguna otra definición se ha dado en torno a la Ocupación, ni en el Cuarto Convenio de Ginebra ni en el Protocolo, por lo que esta definición es la que se retiene a nivel internacional.

Según esta definición, la ocupación puede ser total o parcial, es decir de una parte sólo del territorio, posibilidad esta última que sí que está recogida en el artículo 2 de los Convenios de Ginebra de 1949, al hablar de "ocupación total o parcial del territorio". Evidentemente, la ocupación, aunque se vea enemistosa, esto no quiere decir en absoluto que sea ilícito, a pesar de que consista en la sustitución sobre un determinado territorio de una Parte Contratante, o sobre todo el territorio, de la autoridad del Estado ocupado por la autoridad de la Potencia Ocupada, todo esto sin que haya aceptación o consentimiento de la Parte que se considera soberana sobre ese territorio.

Así las cosas, lo más relevante para que se pueda hablar de una Ocupación es saber si el territorio en cuestión está de hecho ocupado o no, lo que va a requerir un control del territorio. Por lo tanto, no se va a tratar de un mero estacionamiento de tropas durante una determinada invasión o ataque. Va a ser ese control del territorio lo que va a permitir establecer una cierta organización y un grado de estabilidad en el poder que se va a ejercer sobre ese territorio por el poder establecido por la Potencia Ocupante, excluyendo así la autoridad de la Potencia Ocupada sobre el territorio objeto de ocupación. Es decir, la sola presencia militar de fuerzas enemigas para llevar a cabo un ataque o incluso una invasión en territorio enemigo no es suficiente para poder afirmar que hay un control de hecho sobre el territorio al mando de una "autoridad" tal y como prevé el Reglamento de La Haya ${ }^{7}$. Es ese control del territorio el que tiene que permitir

\footnotetext{
${ }^{7}$ Esta distinción entre invasión y ocupación ya fue hecha por el Tribunal americano de Nuremberg en el Asunto Von List and others (Hostages case), en el que de forma precisa se señala lo siguiente: "The term invasion implies
} 
que la autoridad en cuestión no solo que esté allí, sino que "esté en condiciones de ejercerse", como prevé el artículo 42 del Reglamento de La Haya. La Corte Internacional de Justicia lo dejó muy claro en el Asunto de las actividades armadas en el territorio del Congo, cuando sobre esta cuestión señaló de forma rotunda que la Corte debe asegurarse que las fuerzas armadas ugandesas presentes en la RDC (República Democrática del Congo) no estaban solo estacionadas en tal o tal lugar, sino que ellas habían sustituido a la autoridad del Gobierno congolés por la suya ${ }^{8}$.

Este control efectivo sobre el territorio es el que da a la Potencia Ocupante el poder y la autoridad de administrar el territorio a pesar de que el título soberano lo mantenga la Potencia Ocupada. En una situación normal, ambos se encuentran evidentemente en manos de esta última ${ }^{9}$. Es más, no es necesario para que se tenga que aplicar el régimen de Ocupación que la Potencia Ocupante declare ese territorio como ocupado o que se pronuncie diciendo que no es Potencia Ocupante ${ }^{10}$. Y es que como ha señalado Benvenisti, en algunos casos, sobre todo durante las últimas décadas, las Potencias Ocupantes se negaban a reconocer su efectiva presencia en el territorio ocupado por las connotaciones negativas que esto podría acarrearlas sobre todo a nivel político, salvo el caso de Israel que, abiertamente, se ha considerado como Potencia Ocupante de facto sobre los territorios que ocupó durante la Guerra de los Seis días en $1967^{11}$. Esta idea fáctica está recogida, además, en algunos manuales internos relativos al Derecho de los conflictos armados, como el del Reino Unido ${ }^{12}$ y otros países como Australia, Alemania, los Estados Unidos y Argentina ${ }^{13}$. Respecto al Estado español, el Real Decreto 96/2009, de 6 de febrero de 2009, por el que se aprueban las Reales Ordenanzas para las fuerzas

a military operation while an occupation indicates the exercice of governmental authority to the exclusión of the established government. This presupposes the destruction of organised resistance and the stablishment of an administration to preserve law an order. To the extencd that the occupant's control is maintained and that of the civil government eliminated, the area will be said to be occupied". Véase. Trial of Wilhelm List and others (The Hostages case), US, Military Tribunal at Nuremberg, Case № 47 Reports of Trials of War Ciminals, Vol. VIII, 1949, p. 55-56. Para un estudio completo sobre la Ocupación, véase el número 885 de la International Review of the Red Cross (Int,Rev.Red.Cross), dedicado íntegramente a la Ocupación, pp.5-346

${ }^{8}$ Affaire des activités armés sur le territoire du Congo (Répúblique Démocratique du Congo c. Uganda), CIJ (19 de diciembre 2005, párrafos 166-180, especialmente párrafo 177). Hay que apuntar que la Corte recoge literalmente los términos utilizados por el artículo 42 del Reglamento de La Haya cuando dice que "se considera como ocupado un territorio cuando se encuentra colocado de hecho bajo la autoridad del ejército enemigo, y la ocupación se extiende a los territorios donde esa autoridad esté establecida y en condiciones de ejercerse". Para más detalles sobre esta cuestión, véase. Haupais, Nicolas: "Les obligations de la Puissance occupante au regard de la jurispradence et de la pratique recentes", RGDIP (2007), pp. 119 y ss.

${ }^{9}$ Cuyckens, Hanne: "The law of Occupation", en Wouters, Jan. De Man, Philip., Verlinden, Nele (eds) (2016): Armed Conflicts and the Law Intersentia Antwert, Intersentia, Antwerp, pp. 417-444.

${ }^{10}$ A este respecto, véase. Greenwood, Christopher.: "The Administration of Occupied Territory in International Law", en Playfair, Emma (ed.) (1992): International Law and the Administration of Occupied Territories, Oxford, Clarendon Press, pp. 250-265. Ver también International Humanitarian Law and the Challenges of Contemporaryu Armed Conflicts, Report prepared by the International Commettee of the Red Cross, Geneva, 31 nd International Conference of the Red Cross and Red Crescent, octubre 2011, pp. 26-27. Esto mismo vuelve a estar recogido en el Informe International Humanitarian Law and the Challenges of Contemporary Armed Conflicts, preparado por el CICR en la $32^{\mathrm{a}}$ International Conference of the Red Cross and Red Crescent, Geneva, 8-10 diciembre 2015, p. 11.

${ }^{11}$ Este autor señala estas ideas en los términos siguientes: "Using sophisticated claims, all occupants in the past three decades avoided acknowledging that their presence on foreign soil was in fact an occupation subject to the Hague Regulations or Fourth Geneva Convention (except for Israel, on a de facto basis, in parts of the áreas occupied in June 1967). The shunning of the rules of the Hague Regulations and the Fourth Geneva Convention by most occupants is reflected in contemporary legal discourse wich, by and large has also failed to apply them to recent practice. Benvenisti, Eyal: Water Conflict During the Occupation of Iraq", AJIL, vol. 97, no 4 (October 2003), p. 860, nota 2.

${ }^{12}$ The Manual of the Law of Armed Conflict, Oxford University Press, Oxford, 2004, párrafos 11. 2-4.

${ }^{13}$ A este respecto, véase. Ferraro, Tristan: "Determining the Beginning and End of an Occupation under International Humanitarian Law”, Int. Rev. Red. Cross (2012), p. 138, nota 16. 
armadas hace un reenvío general al Derecho internacional humanitario cuando recoge en su artículo 85 con el título de "Principio de humanidad" que "su conducta en el transcurso de cualquier conflicto u operación militar deberá ajustarse a las normas que resultan aplicables de los tratados internacionales en los que España fuera Parte, relativos al Derecho internacional humanitario" ". En nuestra opinión, una mención al Derecho consuetudinario en la materia no hubiera venido mal, al incrementar por esa vía el espectro de normas aplicables. Y es que por mucho que se diga que este marco jurídico convencional es también consuetudinario, es cierto que en el Protocolo I no todas sus disposiciones son consuetudinarias.

\section{El test de la Ocupación: sus elementos esenciales}

El examen o el test del control efectivo para calificar a una Potencia como Ocupante ha dado lugar a ciertas controversias en relación con el ejercicio y la capacidad de ese control ${ }^{15}$. Es más, no han faltado autores relevantes que se han mostrado muy críticos no sólo con el concepto de la Ocupación, sino con el Derecho internacional humanitario en general, como Michel Veuthey ${ }^{16}$. En torno al concepto de la Ocupación señala sin complejos que "la notion d'occupation est juridiquement inopérante ou contestée dans pratiquement tous les conflits contemporains, y compris ceux de la guérrilla"17. Es más, vuelve a la carga indicando que "le critère déterminant pour l'application spatiale du droit humanitaire serrait ainsi être la présence de victimes plus que la qualification juridique ou politiques des territoires en question" ${ }^{18}$. No obstante, si lo que señala este autor nos parece muy acertado, esto ocurre también con otros muchos conceptos abstractos del Derecho internacional, cuyos contornos o límites son poco claros o incluso confusos.

Dicho esto, se ha debatido mucho en torno al concepto de la Ocupación sobre la cuestión de saber si el control tiene que ser actual o si, por el contrario, bastaría con tener la potencialidad para ejercerlo. Esta última tesis, que está en parte recogida en el manual militar de los Estados Unidos $^{19}$, pero que puede presentar problemas en algunos casos si la Ocupación se deja al mero criterio de "potencialidad", y sobre todo cuando este concepto se deja bajo el prisma de una

${ }^{14}$ Real Decreto 96/2009, de 6 de febrero por el que se aprueban las Reales Ordenanzas para las fuerzas armadas, BOE, núm. 33, de 7 de febrero de 2009.

15 ¿Significativas son a este respecto las palabras de Adam Roberts, cuando en su estudio "What is a Military Occupation? BYIL, 1984, pp. 249-305, lo inicia recurriendo al pensamiento siguiente: "Although there is a substantial body of international law which relates to military occupation, the scope application of this law has been perennially problematical. The foreign military involvements of States, not least in the post-1945 world, have taken place in a bewildering variety of forms. Many recent and contemporary cases... raise a difficult question: what exactly is a military occupation?... Who determines whether a particular situation is to be called an occupation? Can the relevent body of law be applicable even in situations where the terme 'occupation', with all its emotional overtones, is rejected by one or another party? Is there one law of military occupation, or is there a combination of rules whieh may vary somewhat depending on the type of occupation?". Ver p. 249.

${ }^{16}$ Ver Veuthey Michel (1983): "Guérrilla et droit humanitaire”, CICR, especialmente pp. 351 y ss., en donde hace todo un rosario de críticas a este sector del Derecho internacional.

${ }^{17}$ Ibid, p. 355.

${ }^{18}$ Ibid.

${ }^{19}$ The Law of Land Warfare-Field Manual, july 1956, Washington DC, par. 356. Este párrafo lleva por título "Effectiveness of Occupation", y reza así: "It follows from the definition that belligerant occupation must be both actual and effective, that is the organized resistance must heve been overcome and the force in possession must have taken measures to stablish its autohority. It it sufficient that the occupying force can, within a reasonable time, send detachments of troops to make its authority felt withim the occupied district. It is immaterial whether the authority of the occupant is maintained by fixed garrisons or flying columns, wether by small or lange force, so long as the occupation is effective. The number of tropos necessary to maintain effective occupation will dependon various considerations such as the position of the inhabitants, the number and density of population, the nature of the terrain and similar factors. The mere existence of a fort or defended area withim the occupied district, provide the fort or defended area is under attack, does not render the occupation of the remainder of the district ineffective. Similarly, the mere existence of local resistence groups does not render the occupation "ineffective". 
mera hipótesis. Y es que en realidad el régimen de la Ocupación no se define pura y simplemente por el establecimiento de una administración militar, sino que, como señala Nicolás Haupais, es necesario que la Potencia Ocupante controle el territorio, lo que revela que es necesario una administración efectiva para poder prevenir o impedir una eventual anarquía ${ }^{20}$. Es más la ausencia de este control efectivo puede dar lugar a que surjan grupos armados insurgentes que, en un momento dado, pueden dar lugar a enfrentamientos militares como los ocurridos en Faluya (Irak) en las denominadas "batallas de Faluya I y II durante el año 2004, a causa precisamente de que el Gobierno provisional iraquí había solicitado a los Estados Unidos y al Reino Unido, Potencias Ocupantes, tal y como reconoció la Resolución 1483 del Consejo de Seguridad, de 22 de mayo de $2003^{21}$, que el control de la ciudad fuera transferido a una fuerza de seguridad local, dirigida por iraquíes, fuerza que comenzó a almacenar armas y a establecer fuertes defensivos por toda la ciudad durante la mitad del año 2004. El resultado fue la creación de grupos importantes insurgentes contra los que las Potencias Ocupantes, sobre todo las fuerzas estadounidenses, tuvieron que hacer frente, desencadenando la Operación "Phantom Fury", y dando lugar a batallas encarnizadas en toda la ciudad, sobre todo en la segunda batalla de Faluya, con un importante número de bajas por ambos bandos ${ }^{22}$.

Evidentemente, esto va en contra de lo que sostuvo en el ya citado caso List y otros el Tribunal militar de Nuremberg, que afirmó lo siguiente: "A commanding general of occupied territory, having executive autyhority as well as military command, will not be heard to say that a unit taking unlaw ful orders from someone other tan himself, was responsible for the crime and that he is thereby absolved of responsibility. It is here claimed, for exemple, that certain SS units under the direct command of Heinrich Himmler committed certain of the atrocities herein charged without the aknowledge, consent or approval of these difendants. But this cannot be a defence for the commanding general of occupied territory. The duty and responsibility for maintening peace and order, and the prevention of crime rests upon the commanding general. He cannot ignore obvious facts and plead ignorance as a defence" 23 . Este caso, sumamente interesante para lo que ahora estamos comentando, prosigue señalando además, que en el caso de que se ponga subordinados para ejercer ese control, la responsabilidad última de lo que ocurra es de la Autoridad competente, es decir, de la Potencia Ocupante, o lo que es lo mismo: "dereliction of duty rests upon him".

Sobre estas dos batallas de Faluya conviene dejar claro que la Primera tuvo lugar durante el período vigente de Ocupación previsto por la Resolución 1483 del Consejo de Seguridad, del 22 de mayo de 2003, y se pone fin, teóricamente hablando el 30 de junio de 2004, al amparo de la Resolución 1546 del también Consejo de Seguridad, del 8 de junio de 2004. Por la primera de estas dos Resoluciones lo que hace el Conejo es pura y simplemente reconocer lo que en realidad existía, es decir la toma del control de Irak por parte en este caso de las Potencias Ocupantes, que se denominaría la Autoridad, sustituyendo así a la hasta entonces Autoridad provisional de la Coalición, a la que se había otorgado el conjunto de los tres poderes, es decir el legislativo, el ejecutivo y el judicial. La segunda Resolución pone fin, teóricamente hablando, a este período, aunque no dejaba de ser una auténtica ficción a la luz de lo que estaba ocurriendo

\footnotetext{
${ }^{20}$ Haupais, Nicolas. : "Les obligations de la puissance ocupante...", op. cit., p. 120.

${ }^{21}$ Bermejo García, Romualdo: "La guerra de Irak y el Derecho Internacional humanitario (DIH)", en: Ramón Chornet, C. (Ed.): Derechos y libertades ante las nuevas amenazas a la seguridad global”, Tirant Lo Blanch, 2005, pp. 11-31. Ver también, Paust, J.J.: "The U.S. as Occuping Power Over Portions of Irak and Relevant Responsibilities Under the Laws of the War", ASIL, vol. 8 (April 2003) en http://www.asil.org/insights/insight102.htm; y "La ONU levanta las sanciones a Irak y reconoce la plena autoridad de EE.UU", El País, de 23 de mayo de 2003.

${ }^{22}$ Se habla de que en esta batalla hubo 106 muertos, de los cuales 95 estadounidenses, y de parte insurgente en torno a 1400 muertos y 1500 prisioneros.

${ }^{23}$ List and others (Hostages case) op. cit., pp. 69-70.
} 
sobre el terreno ya que de hecho el conflicto continuaba y, por lo tanto, había que seguir aplicando el artículo 42 del Reglamento de La Haya. Es evidente que las interferencias del Consejo de Seguridad en el caso iraquí son evidentes, como bien lo expuso en su momento el Profesor Rafâu Ben Achour ${ }^{24}$. Por lo tanto, en nuestra opinión, tanto la batalla de Faluya I como la II se han desarrollado en la práctica en un régimen de Ocupación. Además, es evidente que, en el caso de Irak, la Resolución 1483 no crea la Ocupación, sino que la reconoce pura y simplemente, pues Irak estaba ocupada desde el 1 de mayo de 2003, y así lo anunció y reconoció el propio Presidente de los Estados Unidos, al anunciar el fin de las principales operaciones militares. Es más, siete días más tarde anuncian la creación de la Autoridad Provisional de la Coalición con la función de ejercer sobre el terreno los poderes de gobierno que sean necesarios para proveer de seguridad a la zona y de la ayuda humanitaria, así como para eliminar las armas de destrucción masiva, armas que, como se sabe, nunca aparecieron. Por lo tanto, la Resolución 1483 es declarativa, pues de facto los Estados Unidos y el Reino Unido ya eran Potencias Ocupantes ${ }^{25}$.

Así las cosas, cuando de facto tenemos una Ocupación sobre un territorio, el reconocimiento de la Ocupación por parte del Estado o Estados que lo han invadido y ocupado no es constitutivo, sino pura y simplemente declarativo ${ }^{26}$. Es más, la legalidad o la ilegalidad de la intervención militar que ha propiciado la Ocupación no afecta para nada al hecho de que se tenga que aplicar el régimen de la Ocupación.

$\mathrm{Y}$ es que no siempre que se transfiere la autoridad de la Ocupación al Gobierno local, o incluso cuando se llega a aceptar por el Gobierno local la presencia de las tropas, se pone fin a la Ocupación, ya que para poner fin a la ocupación esta debe ser efectiva. La razón es evidente, pues sino se examina esta cuestión, sería muy fácil nombrar una autoridad local sin más para no seguir teniendo que asumir las reglas de un régimen de la ocupación, cuando en realidad este sí que existe. Como se ha señalado, “... the occupying power cannot discard its obligations by installing a puppet government or by pressuring an existing one to act on its behalf. In all these cases, the occupying power maintains de facto-albeit indirectby full control over the territory" 27 .

De esta cuestión, que es clave para comprender realmente si se es o no Potencia Ocupante, se ocupó también el Tribunal Penal Internacional para la antigua ex-Yugoslavia en el asunto Naletilic ${ }^{28}$, en donde se aborda el nivel de poder requerido para que se pueda considerar si realmente hay Ocupación o no. Y este Tribunal mantiene unas tesis muy estrictas, pues no sólo se queda con el concepto de control global, sino que va más allá al exigir un dominio sobre el territorio, o lo que es lo mismo un control efectivo. Desde este prisma, los

\footnotetext{
${ }^{24}$ De este autor, véase :. "La résolution 1546 du Conseil de sécurité ou l'apogée de l'art de la fection”, Actualité et droit international, juillet 2004, 8 p. Este estudio se puede ver también en

www.ridi.org/adi/artcles2004/200407bac.pdf . Sobre el régimen de ocupación en Irak, véase también Starita, Massimo: "L'occupation de l'Irak, le Conseil de sécurité, le droit de la guerre et le droit des peuples à disposer d'eux mêmes", RGDIP (2004), pp. 884-916; Tigroudja, Hélène : "Le régime d'occupation d'Irak", AFDI (2004), pp. 77-101; y Haupais, Nicolas.: "Les obligations de la Puissance ocupante...”, op. cit., pp. 125-130.

${ }^{25}$ Kolb, Robert y Vité, Silvain : 'L'applicabilité ratione temporis du droit de l'occupation de guerre : le debut et la fin de l'occupation", en Chetail, Vicent (ed.) (2013) : Permanence et mutations du droit des conflits armés, Bruylant, Bruselas, pp. 170-171, en donde se aborda el caso de Irak.

${ }^{26}$ Benvenisti, Eyal.: "Water Conflicts During the Occupation of Irak", AJIL (2003), p. 861; Roberts, Adam.: "What is Military Occupation?", BYIL (1984), p. 256. Esta cuestión ya la dejó clara Gerhard von Glahm en 1957 en su estudio The Occupation of Enemy Territory-Commenmtary on the Law and Practice of Belligerent Occupation, Minnesota, 1957, p. 28.

${ }^{27}$ Dörmann, Kunt. y Colassis, Laurent.: "International Humanitarian Law in the Irak Conflict", GYIL (2004), p. 309.

${ }^{28}$ A este respecto, véase Prosecutor v. Mladen Naletilic and Vinko Martinovic, Case No IT-98-34-Y, de 31 de marzo de 2003, especialmente párrafos 214-217.
} 
criterios esenciales a retener para una evaluación sobre ese control efectivo, serían los siguientes: a) la Potencia Ocupante debe establecer su propia autoridad y sustituir a la de la Potencia Ocupada, al no poder ésta funcionar públicamente; b) las fuerzas enemigas o bien ya se han rendido, ya han sido vencidas o se han retirado de la zona; c) la Potencia Ocupante dispone sobre el terreno de fuerzas suficientes que le permitan imponer su autoridad, o enviarlas en un plazo razonable; d) debe haberse ya establecido una administración provisional sobre el territorio; y e) la Potencia Ocupante ya ha comprobado que las órdenes dadas a la población civil o bien se han cumplido motu proprio o ha podido obligar a ejecutarlas. Evidentemente estas condiciones hay que interpretarlas con un cierto margen de discrecionalidad, es decir, deben ser criterios que permitan aclarar ciertas situaciones que pueden tener una cierta complejidad, como puede ser el caso de la Franja de Gaza, pero que pueden ser relevantes en el caso de que haya ciertas dudas ${ }^{29}$.

Desde esta perspectiva, es evidente que si hay tropas sobre el terreno, es decir lo que se ha denominado "the Boots on the Ground", sí hay una autoridad sobre el territorio ocupado que puede controlar y vigilar que se respeten las normas concernientes al régimen de la Ocupación, y todo esto será más fácil tanto para la Potencia Ocupante como para la población del territorio ocupado, siempre y cuando, claro está, se cumpla con el segundo criterio anteriormente expuesto, es decir que las fuerzas enemigas se hayan rendido, vencidas o hayan huido, lo que implica que no hay ya una resistencia organizada como tal, aunque esto no quiere decir que no pueda haber todavía ciertas escaramuzas u operaciones militares de resistencia como fue el caso en Irak. Sin embargo, tras la guerra en Libia contra el régimen de Gadafi al amparo engañoso de la protección de la población civil, objetivo este último presente en las resoluciones del Consejo de Seguridad de las Naciones Unidas que propiciaron la intervención, nunca se ha hablado de una Ocupación del territorio por parte de algunos de los Estados intervinientes en el conflicto, pura y simplemente porque no hubo tropas en tierra, al menos de una forma significativa, para poder controlar el territorio, de ahí las ejecuciones sumarias y matanzas que tuvieron lugar tras el conflicto. Y es que es en realidad casi imposible proteger a la población civil solo desde el aire si no se tienen fuerzas en tierra. Y esto fue lo que generó el caos en Libia, ya que una vez que los países intervinientes derrocan y matan al líder libio, se desentienden de una forma egoísta e inmoral de todo lo que ocurriría en Libia, cuyas consecuencias las estamos padeciendo todavía hoy ${ }^{30}$. No obstante, para algunos esta intervención fue considerada como ejemplar, como por ejemplo para el belga Chris De Cock, del Ministerio de Defensa belga, país que intervino de forma muy activa en los bombardeos, para quien "(The) Operation Unified Protector offered convincing proof that airpower is flexible enough to take the lead in many fifferent types of conflict. In targeting enemy forces, NATO forces strictly adhered to their obligations under the law of armed conflict. Targets were positively identified pior to prosecution and all feasible precautions were taken in order to minimize damage to civilian property and the civilian propulation" 31 .

\footnotetext{
${ }^{29}$ Sobre estos criterios, ver Kolb, R. y Vité, S.: Le droit de l'occupation militaire..., op. cit., pp. 139 y ss.

${ }^{30}$ Sobre este conflicto, ver los estudios publicados en el Anuario Español de Derecho Internacional, 2011 de los autores siguientes: Bermejo García, Romualdo: "La protección de la población civil en Libia como coartada para derrocar un gobierno: un mal inicio para la responsabilidad de proteger”, pp. 9-55; Gutiérrez Espada, Cesáreo: “Sobre el ‘núcleo duro' de la Resolución 1973 (2011) del Consejo de Seguridad y acerca de su aplicación práctica”, pp. 57-75; Cervell Hortal, María José: “La Resolución 1970 (2011) del Consejo de Seguridad y la remisión de la cuestión libia a la CPI: ¿la unión hace la fuerza?”, pp. 77-107; López-Jacoiste Díaz, María Eugenia: "La crisis de Libia desde la perspectiva de la responsabilidad de proteger", pp. 109-152; "Cuestiones en torno a la legitimidad del Consejo Nacional de Transición Libio a raíz de su reconocimiento por la Asamblea General de las Naciones Unidas", pp. 153-183; y Echeverría Jesús, Carlos.: "Revueltas, guerra civil tribal e intervención militar extranjera en Libia", pp. 85-201

${ }^{31}$ De Cock, Chris (2011): “Operation Unified Protector and the Protection of Civilians in Libia”, Yearbook of International Humanitarian Law, pp. 213-235., texto precitado en p. 233.
} 
A este respecto, conviene señalar que a pesar de que en Irak la invasión fue todo un éxito, no ocurriría lo mismo con el posconflicto y la ocupación, al pensar que casi ya todo se había terminado con la toma de Bagdad y la caída del régimen de Sadam Hussein. Así las cosas, el establecimiento de unas fuerzas de ocupación que bajo el mando de una Autoridad competente controlen el territorio va a ser una protección para la población del territorio ocupado ${ }^{32}$.

Un elemento importante a destacar en torno a esta cuestión es que el Tribunal Europeo de Derechos Humanos se ha pronunciado inequívocamente sobre el tema de la Ocupación afirmando que la teoría de "boots on the ground" es un requisito imprescindible para poder hablar de Ocupación, y lo hace en términos que no da lugar a dudas, al señalar lo siguiente:

"Military occupation is considered to exist in a territory, or part of a territory, if the following elements can be demonstrated: the presence of foreign troops, wich are in a position to exercice effective control without the consent of the sovereign. According to widespread expert opinión physical presence of foreign troops is a sine qua non requirement of occupation, ie occupation it not conceivable without 'boots on the ground', therefore forces exercising naval or air control through a naval or air blockade do not suffice" ${ }^{, 33}$.

Esta contundente afirmación sería después retenida en los mismos términos en el caso Chigarev and Others v. Armenia, al haber unido en la Gran Sala ambos casos ${ }^{34}$. Las sentencias del Tribunal de Estrasburgo son categóricas, aunque en nuestra opinión son correctas, a la luz de lo que estaba detrás en ambos casos, al tratarse de personas desplazadas que no podían acceder a sus propiedades en las zonas afectadas por el conflicto, sobre todo en el caso de Sargsian, al invocar el demandante la imposibilidad de volver al pueblo de Gulistán, que está situado en territorio de Azerbaiyán, pero muy cerca de la línea que divide este territorio de las fuerzas separatistas de Nagorno-Karabaj, estando así fuera del control del Gobierno de Azerbaiyán, e inaccesible por lo tanto a los civiles ${ }^{35}$. Esto fue lo que llevó al Gobierno de Azerbaiyán a hacer en el momento de la ratificación del Convenio Europeo de Derechos Humanos la siguiente declaración: "The Republic of Azerbaijan declares that it is unable to guarantee the application of the provisions of the Convention in the territories occupied by the Republic of Armenia until these territories ave liberated from that occupation" 36 . Frente a esta declaración que hace Azerbaiyán, el Tribunal de Estrasburgo responde con las afirmaciones precitadas. Estas sentencias suscitaron rápidamente alguna respuesta en algunos autores, como Marco Milanovic, al señalar que el Tribunal Europeo de Derechos Humanos decide que Israel no es Potencia Ocupante en la Franja de Gaza ${ }^{37}$

\footnotetext{
${ }^{32}$ Sobre esta cuestión, véase Ben-Naftall, O.: "Belligerant Occupation: a Plea for the establishment of an International Supervisory Body Mechanism”, en: Cassesse, Antonio (ed.) (2012): Realizing Utopia: the Future of International Law, Oxford University Press, Oxford, pp. 541-542; y Ferraro, Tristan: "Determining the Beguinning and End of an Occupation under International Humanitarian Law", Int. Rev. Red.Cross (2012), pp. 143 y ss. Este autor, después de hacer un exhaustivo análisis de las pormenoridades que encierra esta cuestión señala lo siguiente: "In light of the above, it can be asserted that the presence of hostile military forces on foreign territory is -in most cases- a necessary condition for describing that territory as 'occupied'. While the presence of foreign troops may not be sufficient to cause an area to be classified as occupied territory, it is nonetheless a prerequisite because it generally povides the necessary conditions for the exercice of effective control. Finally, requiring the presence of foreign forces in the occupied territory conforms to the principle of effectiveness underlying occupation law, according to wich the Occuppying Power must be capable of enforcing rights and duties under occupation law", p. 147.

${ }^{33}$ Ver ECT-IIR-Case of Sargsyan v. Azerbaiyan, Application no 40167/06, 16 june 2015, párrafo 94.

${ }^{34}$ Ver, Chigarov and Others v. Armenia, Application no 13216/06, de 16 de junio de 2016, párrafo 96.

35 Párrafos 83 y ss. Relativos a las leyes de la República de Azerbaiyán.

36 Párrafo 93.

${ }^{37}$ A este respecto, véase. Milanovic, Marco.: "European Court Decides that Israel is not Occupping Gaza", EJIL Talk!, 17 june 2015; ídem en ejitalk org/european-court-decides-that-israel-is-not-occuping-gaza/ Este autor señala que duda mucho de que los jueces fueran conscientes de las implicaciones que unas afirmaciones tan categóricas
} 
En relación con las tropas ocupantes el Tribunal de Estrasburgo no dice que las fuerzas sobre el terreno deben ser siempre las mismas en cuanto a sus capacidades militares, pues esto dependerá de cada caso y de cómo va la Ocupación. Por ejemplo, no sería lo mismo si hay grupos de resistencia que si no los hay, o si la Ocupación es aceptada de buen grado por la población o si no lo es. Así las cosas, lo cierto es que no se entienden muy bien las tesis que de una manera directa o indirecta hacen abstracción de esta presencia militar en la zona ocupada, ya que el artículo 43 del Reglamento de La Haya impone a la Potencia Ocupante la obligación de mantener el orden público y la seguridad. Así las cosas ¿se puede mantener el orden público y la seguridad sin tener fuerzas en la zona? Si además pensamos que los actos ilícitos cometidos en la zona ocupada son imputables a la Potencia Ocupante ¿Cómo esta va a garantizar que estos actos no se cometan? Pensando en Gaza ise le ha ocurrido a algunos atribuir a Israel responsabilidad por los asesinatos cometidos por Hamás a sus opositores tras el abandono del territorio?

Estas tesis que acabamos de comentar, sobre todo la de Marco Milanovic, no las comparte el israelí Yoram Dinstein, quien ha defendido en 2009 que la Ocupación no puede basarse únicamente en el poder aéreo o naval, aunque en relación con Gaza ha considerado que sigue siendo territorio ocupado, al mantener Israel, entre otras cosas, el control aéreo y marítimo $^{38}$. No sabemos si el Profesor Dinstein sigue manteniendo el mismo pensamiento tras las tres guerras que Israel y Hamás han llevado a cabo en 2008/9, 2012 y 2014, guerras que han movilizado a decenas de miles de soldados del Tsahal y que han causado numerosas bajas israelíes y miles de muertos palestinos en Gaza, tanto milicianos de Hamás como civiles ${ }^{39}$.

Surgen, además, otras cuestiones que revelan la necesidad de tener "boots on the ground" por utilizar la expresión más sucinta en relación con este tema. Y es que lo que hace el Tribunal de Estrasburgo no es ni más ni menos que confirmar lo que ya señaló la Corte Internacional de Justicia en el ya mencionado Asunto de la República Democrática del Congo contra Uganda en 2005 cuando señaló que "La Cour doit s'assurer que les forces armées ugandaises présentes en RDC n'étaient pas seulement stationnées en tel ou tel en droit, mais qu'elles avaient égulement substitué leur propie autorité à celle du gouvernement congolais" 40 . Y siguiendo un hilo conductor lógico la Corte señala que investigará "si des parties du territoire de la RDC étaient placées sous l'autorité de l'armée ougandaise au sens de l'article 42 du Règlement de La Haye..."41, para una vez comprobados los elementos de hecho que responden a los criterios establecidos en el precitado Reglamento de La Haya sentencia "que l'Ouganda était une puissance ocupante dans le district de l'Ituri à l'époque pertinente. En tant que tel, il se trouvait dans l'obligation, énoncée dans l'article 43 du Règlement de La Haye de 1907, de prendre toutes les mesures qui dépendaient de lui en vue de retablir et d'assurer autant qu'il était posible, l'ordre public et la sécurité dans le territoire occupé en respectant, sauf obsolu, les lois en vigueur en RDC" 42 .

Así las cosas, la Potencia Ocupante tiene no solo que respetar y hacer respetar el Derecho internacional humanitario tal y como reza el artículo primero común a los cuatro

como éstas podían causar, sobre todo para el caso del debate en torno a Gaza. Por eso, señala el autor, con ironía, que Gulistán y Gaza han descubierto que tienen algo en común, y que el Tribunal de Estrasburgo comienza a pisar fuerte en el ámbito del Derecho internacional humanitario.

${ }^{38}$ Dinstein, Yoram: The International Law of Belligenent Occupation, Cambridge, Cambridge University Press, 2009, párrafo 100.

${ }^{39}$ Sobre estos aspectos, véase. infra.

${ }^{40}$ Párrafo 173.

${ }^{41}$ Párrafo 174.

42 Párrafo 178. 
convenios de Ginebra ${ }^{43}$, y que es también derecho consuetudinario según afirmó la Corte Internacional de Justicia en el Asunto de Nicaragua ${ }^{44}$, sino también el Derecho Internacional de los Derechos Humanos. Es sobre esta premisa fundamental que la Corte Internacional de Justicia va a condenar a Uganda al ser considerada como Potencia Ocupante y no haber hecho todo lo que estaba sus manos en el territorio ocupado en la República Democrática del Congo ${ }^{45}$. Es más, en el dispositivo de la sentencia, la Corte condena a Uganda por dieciséis votos y uno en contra, el del juez ad hoc Kateka, por el comportamiento no solo de sus fuerzas armadas, que han cometido homicidios y torturas así como otros tratos inhumanos a la población civil, sino también por la destrucción de pueblos, sin hacer distinción entre objetivos civiles y militares, entrenamiento de niños soldados, haber incitado al conflicto étnico, así como por no haber adoptado medidas para impedirlo, en tanto que Potencia Ocupante. Pero también deja muy claro que no se han adoptado medidas destinadas a respetar y a hacer respetar los derechos humanos y el Derecho internacional humanitario ${ }^{46}$. Repárese, además, que la Corte admite una ocupación por procuración de territorios, es decir, que no estén directamente bajo la autoridad de las fuerzas armadas regulares, sino de grupos rebeldes sometidos y que estén bajo su control, un aspecto que no es desdeñable, sobre todo dados los numerosos conflictos asimétricos que existen hoy en día en la sociedad internacional ${ }^{47}$.

\section{Los territorios ocupados por Israel y sus características}

Hechas todas estas consideraciones, hay que tener presente que no todos los regímenes de ocupación presentan las mismas características, encerrando algunos de ellos una cierta complejidad, como es el caso palestino, sobre todo a raíz de la creación de la Autoridad Nacional Palestina. Y es que, mediante el Acuerdo del 29 de agosto de 1994, firmado en Erez, sobre la transferencia de poderes y responsabilidades a la Autoridad Nacional Palestina, así como por el Acuerdo interino del 28 de septiembre de 1995 (conocido también como Oslo II), Acuerdo que fue firmado en Washington, se concede a la Autoridad Palestina la jurisdicción sobre el $31 \%$ del territorio de Cisjordania (Judea y Samaria para los israelíes), incluyendo las principales ciudades, excepto Jerusalén, capital de Israel y Hebrón. Pero es que, además, este Acuerdo que es muy complejo, y que consta de siete Protocolos, recoge cuestiones relacionadas con la seguridad, relaciones económicas, asuntos civiles, cooperación entre ambas partes, etc. Es más, este Acuerdo recoge en su Capítulo II algunos aspectos que ya se habían abordado en la conocida Declaración de Taba del 11 de agosto de 1995, en la que ya se había previsto elecciones directas palestinas para un Consejo ejecutivo y legislativo, así como la transferencia de la mayoría de las competencias civiles a la Autoridad Palestina. También se estableció un reparto territorial con un complejo sistema de reparto de competencias, como la zona A, que

\footnotetext{
${ }^{43}$ Sobre esta cuestión, véase : Condorelli, L. y Bosson De Chazournes, L. : "Quelques remarques à propos de l'obligation des Etats à respecter et faire respecter le droit international humanitaire en troutes circonstances", en: Etudes et essais sur le droit international humanitaire et sur les príncipes de la Croix-Rouge, Mélanges en l'honneur de J. Pictet, Nijhoff, La Haye, 1984, pp. 17-35.

${ }^{44}$ CIJ, Recueil, arrêt du 27 juin 1986, párrafo 220. En este párrafo la Corte alude no solo al artículo primero, sino también al artículo 3 común que regula los conflictos no internacionales.

${ }^{45}$ La Corte deja meridianamente claras estas tesis al señalar que "Cette obligation comprend le devoir de veiller $\mathrm{du}$ respect des règles aplicables du droit international relatif aux droits de l'homme et du droit international humanitarie, de proteger les habitants du territoire occupé contre les actes de violence et de ne pas tolérer de tels actes de la part d'une quelconque tierce partie". Párrafo 178. Ver también Párrafo 179 y ss. La Corte, en el caso de Uganda contra RDC, recuerda lo que ya señaló en el Asunto relativo a las consecuencias jurídicas de la edificación de un muro en el territorio palestino ocupado (CIJ. Recueil 2004, párrafo 106). Ver también la Opinión individual del Juez Simma, párrafo 37-39.

${ }^{46}$ Párrafo 345.3.

${ }^{47}$ Sobre estos conflictos asimétricos, véase: Redalié, Lorenzo.: La conduite des hostilités dans les conflits armés asymétriques: un défi au droit humanitaire, LGDJ/Schulthess/Collection Genevoise, Ginebra/Zurich/Basilea, 23 mars 2013,378 p.
} 
comprendía las ciudades más importantes cisjordanas, salvo Hebrón, en la que la Autoridad Palestina asumía las competencias en materia de control civil y de seguridad; la zona B, que comprendía una buena parte de los municipios palestinos, en la que la Autoridad palestina asumía las competencias civiles, mientras que Israel asumía las competencias de seguridad; la zona $\mathrm{C}$, que comprendía la mayor parte del ámbito rural, en la que Israel continuaba ejerciendo el control, comprometiéndose a iniciar el redespliegue un año más tarde; y por último la zona $\mathrm{D}$, que abarcaba todos los asentamientos israelíes en Cisjordania y las instalaciones militares, en donde Israel seguía conservando todo el control hasta el final de las negociaciones, previstas para mayo de 1999.

Pero si en Cisjordania se hicieron tres áreas territoriales A, B, y C, más la ciudad de Hebrón, zona D, en la Banda de Gaza se dividió solo en dos: la zona en la que la Autoridad Palestina tenía casi todos los poderes de Gobierno sobre las ciudades, mientras que Israel iba a retener los poderes de Gobierno sobre los asentamientos, las carreteras más importantes, sus fronteras con Israel y Egipto, así como sobre las aguas territoriales y el espacio aéreo. Respecto a la seguridad Israel conservó la autoridad sobre toda la Banda de Gaza. Este reparto funcional de las competencias suscitó muchas incertidumbres respecto al estatuto jurídico de cada zona sometida a la Autoridad Palestina, como apuntó E. Benvenisti, quien expresó la idea de que la Ocupación de la mayoría de la Banda de Gaza se había terminado tras el establecimiento de dicha Autoridad Palestina ${ }^{48}$.

Es evidente la complejidad que encierran estos Acuerdos que se debe como ya se ha señalado por algún autor, a ciertas razones históricas (Mandato británico, ocupación por Jordania hasta 1967 , etc.), y por otro a las dificultades presentes a la hora de enmarcar estos Acuerdos en un ámbito jurídico determinado, al mezclar aspectos internos e internacionales ${ }^{49}$. Todo esto podría hacer ver que la Corte Internacional de Justicia en su Opinión Consultiva sobre el muro pudiera tener ciertas dudas en torno a la cuestión de saber si Israel era o no Potencia Ocupante sobre estos territorios, aunque este no fue el caso ya que a pesar de que Israel señalara que aplicaba el Cuarto Convenio de Ginebra de facto pero no de iure, considera a Israel como Potencia Ocupante de iure $e^{50}$. La Corte deja además muy claro un aspecto controvertido que era defendido por Israel, como era el hecho de que Cisjordania se lo ocupó a Jordania, Parte Contratante en el cuarto Convenio de Ginebra, pero no soberana sobre esos territorios. Este punto de vista es rechazado por la Corte en términos muy claros, al señalar lo siguiente: “... Israel et la Jordanie étaient parties à cette convention lorsque éclata le conflit armé de 1967.

\footnotetext{
${ }^{48}$ Benvenisti, Eyal.:"Responsibility for the Protection of Human Rights under the Israeli Palestinians Agreements", Israel Law Review (1994), p. 312. La misma opinión expresó en el año 2000 Watson, Geoffrey R. (2000): The Oslo Accord: International Law and the Israeli-Palestinian Preace Agreements, New York Oxford University Press, p. 176.

49 Véase, por ejemplo, Mouton, Jean Denis: “L'autonomie palestinienne àprès l'accord intérimaire israelopalestinien du 28 septembre 1995 : originalité, ambiguïté, tensión”, RGDIP (1996), pp. 951-978.

${ }^{50}$ Conséquences juridiques de l'édification d'un mur dans le territoir palestinien occupé, Opinión Consultiva del 9 de julio de 2004, párrafo 78, 89 y 90. Que Israel se haya comprometido a aplicar el Cuarto Convenio de Ginebra es un hecho indiscutible, pues justo después de la Ocupación de Cisjordania tras la Guerra de los Seis Días en 1967, las autoridades israelíes adoptan la Ordenanza $n^{\circ} 3$, que prevé en su artículo 35 que el Tribunal militar “... debe aplicar las disposiciones del Convenio de Ginebra del 12 de agosto de 1949 relativo a la protección de las personas civiles en tiempo de guerra en lo referente a los procesos judiciales. En caso de incompatibilidad entre la presente Ordenanza y el citado Convenio, este último prevalecerá". También lo ha declarado públicamente en varias ocasiones a pesar de que ha defendido que como no se lo había ocupado a una Parte Contratante con soberanía sobre esos territorios, no podría considerarse que, de iure, fuera Potencia Ocupante. A este respecto, véase. Ibid, párrafo 93. Sobre los antecedentes que llevaron a la construcción de la valla, y para unos comentarios sobre la Opinión, véase. Bermejo García, Romualdo. y Pozo Serrano, Pilar.: Una tierra, dos Estados: Análisis jurídico-político del conflicto árabe-isralí, Eunsa, Pamplona, 2011, pp. 275-289. Sobre esta opinión, véase : Rivier, Raphaële : "Conséquences juridiques de l'édification d'un mur dans le territoire palestinien occupé. Cour internacionale de Justice. Avis consultatif du 9 juillet 2004”, AFDI (2004), pp. 292-336.
} 
Dès lors ladite convention et applicable dans les territoires palestiniens qui étaient avant le conflit à l'est de la Ligne Verte et qui ont à l'occasion de ce conflit été occupés par Israel, sans qu'il y ait lieu de rechercher quel était auparavant le statut exact de ces territoires" 51.

La Corte se apoya en su análisis en la interpretación que ha hecho el Comité Internacional de la Cruz Roja en esta materia, así como en el que han hecho los Estados Parte en la Conferencia sobre el Cuarto Convenio de Ginebra que tuvo lugar en 1999, y en la opinión de otros organismos de la Naciones Unidas ${ }^{52}$. Es más, la Corte señala que la misma Corte Suprema de Israel ha considerado en una decisión del 30 de mayo de 2004 que "las operaciones militares de las fuerzas israelíes en Rafah, en la medida en que afecten a personas civiles se rigen por el Reglamento de La Haya de 1907 y por el Cuarto Convenio de Ginebra ${ }^{53}$. Repárese, además, que la Corte considera a Israel como Potencia Ocupante de todos los territorios negociados con la Autoridad Palestina, lo que implica en la práctica que si Israel considera que la Autoridad Palestina viola alguna norma internacional en alguna materia que cae bajo el régimen de ocupación previsto por el Derecho internacional humanitario, la responsabilidad última caería sobre la Potencia Ocupante, lo que implicaría que Israel debería obligar a la Autoridad Palestina por todos sus medios a su alcance a cumplirla.

En nuestra opinión, la posición de la Corte a la hora de tratar esta cuestión nos parece poco fina y de un alcance limitado, pues olvida algo que es consustancial a este conflicto, ya que no se trata de dos Estados con soberanías reconocidas, sino que de un lado teníamos un Estado, Israel, y una entidad de muy difícil calificación con vocación a autodeterminarse en aquella época al estar previsto en esos acuerdos y negociaciones la creación de un Estado palestino. Se actuaba de buena fe y con gran esperanza en el futuro, de ahí el amplio abanico de competencias otorgadas a la Autoridad Palestina, pensando siempre en la creación de ese Estado palestino que debía llegar en 1999.

Es cierto que ese camino era tortuoso, pero también lo es que se había abierto por primera vez un horizonte esperanzador para que de una vez por todas, llegara la paz a la zona. Que la evolución en la región no haya ido por esos derroteros, es cierto, pero esto no tiene por qué conllevar que toda la responsabilidad de un régimen de Ocupación, por decirlo de alguna manera troceado, recaiga sobre Israel como Potencia Ocupante. Y es que no se comprende muy bien cómo se va a poder atribuir a Israel las violaciones cometidas por las autoridades locales palestinas en aquellas zonas que como en la zona A, la Autoridad Palestina tiene plenas competencias en materia civil y de seguridad, en esta última materia salvo en caso de terrorismo. Lo mismo ocurre con la zona B en materia civil, que es competencia palestina. En el caso de violación de Derechos Humanos ¿Sería Israel responsable de esas violaciones? Si este fuera el caso, esto hubiera ya acarreado la denuncia de esos acuerdos, y no solo eso, sino que incitaría a que en las negociaciones entre ambas partes Israel rechazara de plano la transferencia de esas competencias, lo que generaría reintroducir un elemento hostil más al conflicto. Es cierto que, en materia de seguridad, Israel se ha reservado un cierto poder de acción, pero ese no es el caso en materia civil administrativa. Desde este prisma, pensamos que la Corte hubiera debido tener en cuenta esta realidad sobre el terreno, y no solo señalar que es Potencia Ocupante sin abordar estas peculiaridades.

\footnotetext{
${ }^{51}$ Ibid, párrafo 101.

52 Ibid, párrafo 95-99.

${ }^{53} \mathrm{Ibid}$, párrafo 100. A este respecto, conviene apuntar que Israel no es parte en el Reglamento de La Haya, pero lo aplica al considerar que forma parte del Derecho consuetudinario. Para un estudio exhaustivo sobre cómo la Corte Suprema de Israel ha interpretado el Derecho Internacional Humanitario en las zonas ocupadas, véase el interesante estudio de Kretamer, D.: "The Supreme Court of Israel: Judicial Review during Armed Conflict", GYIL, 2004, pp. 792-456.
} 
Así las cosas, la Corte deja claro un aspecto que fue muy controvertido dadas las peculiaridades del caso, y es que en caso de conflicto armado, y por lo tanto también en una Ocupación de territorios, hay que aplicar no solo el Derecho internacional humanitario sino también el Derecho internacional de los Derechos Humanos ${ }^{54}$, confirmando así lo que ya dijo en la Opinión Consultiva sobre la Licitud de la amenaza o del uso de armas nucleares de $2006^{55}$. Esta afirmación de la Corte no toma en consideración las peculiaridades israelo-palestinas que Israel ya había invocado en 1998 al redactar su Informe al Comité de Derechos Humanos de la ONU en relación con la aplicación del Pacto de Derechos Civiles y Políticos. Y es que Israel estimaba que dichos Pactos, tanto el de Derechos Civiles y Políticos, como el Pacto de Derechos Económicos y Sociales no eran aplicables a la situación que reinaba en los territorios ocupados. El Comité, preocupado por la posición de Israel, que no cambiaría en los años posteriores, emitió un Informe en $2003^{56}$ en el que se aborda esta cuestión señalando que en las circunstancias actuales, las disposiciones del Pacto de Derechos Civiles y Políticos se aplican a la población de los territorios ocupados. Por lo tanto, todos los actos llevados a cabo por las autoridades o agentes del Estado parte en estos territorios caen bajo la responsabilidad israelí, de conformidad con los principios del Derecho internacional público ${ }^{57}$.

Todo esto se debe a que Israel ha sostenido que en caso de conflicto armado se aplica el Derecho internacional humanitario como lex specialis, y no el Derecho internacional de los derechos humanos. Esta tesis israelí no solo no es aceptada por la Corte sino que remata señalando no solo que tiene que respetar los Pactos y el Convenio sobre los derechos del niño del 20 de noviembre de 1989, sino que además “... Il est tenu de ne pas faire obstacle à l'éxercice de tels droits dans les domaines où compétence a eté transferée à des autorités palestinientes $" 58$.

Inútil de señalar que esta Opinión consultiva suscitaría una amplia polémica doctrinal por cómo se habían abordado determinadas cuestiones. Ha habido autores muy favorables ${ }^{59}$ y otros más discretos ${ }^{60}$, sin olvidar algunos bastantes críticos ${ }^{61}$. Hay que reconocer, sin embargo,

\footnotetext{
${ }^{54}$ Ibid, párrafo 106. La Corte especifica en este párrafo el marco de relaciones entre el Derecho internacional humanitario y el Derecho internacional de los Derechos Humanos, señalando que pueden presentarse tres situaciones distintas: ciertos derechos pueden ser exclusivamente de Derecho internacional humanitario; otros de los derechos humanos; y otros de ambos cuerpos jurídicos. La Corte tomará en consideración los dos ámbitos de protección, es decir el Derecho internacional de los derechos humanos y, en tanto que lex specialis, el Derecho internacional humanitario.

${ }^{55}$ Licéité de la menace eu de l'emploi d'armes nucléaires, 8 juillet 1996, párrafo 24.

${ }^{56}$ Doc CCPR/CO/78/ISR.

${ }^{57}$ Ibid, párrafo 11. En este Informe el Comité recuerda a Israel las advertencias que ya le hizo a su observación en relación con los territorios ocupados, en el que ya se informaba de que la aplicabilidad del Derecho internacional humanitario durante un conflicto armado no impide de por sí la aplicación del Pacto. Doc. CCPR/C/79/Add. 93, de 18 de agosto de 1998, p. 3, párrafo 11.

${ }^{58}$ Conséquences juridiques de l'édifice d'un mur... op. cit., párrafo 112 in fine.

${ }^{59}$ A este respecto,véase Abi-Saab, Rosemary: “Conséquences juridiques de l'édification d'un mur dans le territoire palestinien occupé. Quelques réflexions péliminaires sur l'avis consultatif de la Cour internationale de Justice", RIC (2004), 633-657.

${ }^{60}$ Bianchi, Andrea.: "Dismanthing the Wall: The ICJ's Advisory Opinion and its likely Impact on International Law”, GYIL (2004), pp. 343-391.

${ }^{61}$ Bermejo García, Romualdo: "La valla de seguridad contra el terrorismo palestino a la luz de la Sentencia de la Corte Suprema de Justicia israelí de 30 de junio de 2004", REDI (2004), pp. 1035-1042; ídem "Israel y la valla de seguridad contra el terrorismo palestino", en Soberanía del Estado y Derecho internacional. Homenaje al Prof. Juan Antonio Carrillo Salcedo, Universidad de Córdoba, Sevilla y Málaga, Sevilla, 2005, pp. 219-238; ídem "Comentarios en torno a la Opinión Consultiva de la Corte Internacional de Justicia sobre el mal denominado 'muro' de Israel contra el terrorismo palestino: una Opinión muy 'opinable'”, en: Ramón Chornet, Consuleo (coord.) (2006): Uso de la fuerza y protección de los derechos humanos en un nuevo orden internacional, Tirant lo Blanc, Valencia, pp. 131-173; López-Jacoiste Díaz, María Eugenia.: “Algunas reflexiones sobre la Opinión Consultiva sobre el muro: la solución está en Ramalla y Gaza y no en La Haya o Manhattan”, Anuario de Derecho
} 
que casi quince años después de adoptarse esta Opinión, no parece que sus consecuencias hayan sido tal y como se abordaron por la Corte, por lo menos en relación con la seguridad y el terrorismo. Y ahí sigue la valla... Además, es interesante constatar las divergencias evidentes entre la Opinión de la Corte y la decisión de la Corte Suprema de Justicia israelí, adoptada tan solo nueve días antes que la Opinión Consultiva que va por derroteros completamente distintos.

Como la Corte no ha tomado en consideración todas estas especificidades presentes en el caso, esto conllevaría en muchas ocasiones a que la Potencia Ocupante, en este caso Israel, tuviera que llevar a cabo una fuerte penetración en las estructuras económicas, políticas y sociales palestinas, para adoptarlas a la protección de esos derechos humanos, acción que sería mal recibida por la población palestina, pues lo consideraría no solo como una simple violación de los Acuerdos firmados por la Autoridad Palestina con Israel, sino también como una injerencia en sus estructuras sociales y como una violación incluso del derecho de autodeterminación, derecho que hoy por hoy es el único que pueden invocar para crear su Estado. Esto nos lleva a preguntarnos si no sería conveniente pensar en ir elaborando unas reglas de ocupación o un nuevo régimen jurídico en esta materia que permitiera llevar a cabo, en casos en los que fuera necesario, esas transformaciones y reformas necesarias con el fin de poder construir lo que se ha denominado la "nation building". Esto se podría aplicar a casos como el de Irak o los territorios palestinos, por citar dos ejemplos con orígenes distintos y que tienen sus propias peculiaridades ${ }^{62}$, aunque quizás el reto sea mayor de lo esperado.

No obstante, sí que pensamos como Raphaële Rivier, cuando señala al examinar los párrafos 136 a 140 de la Opinión de la Corte que “... il manque manifestement un examen des faits permettant de démontrer pourquoi les justifications avancées par Israël sont insuffisantes. En définitive, la Cour s'abstient de proceder à une réelle réfutation des arguments israéliens. Elle n'examine pas les éléments de faits pertinents concernant certaines parties précises du mur, les impératifs de défense auxquels elles répondent et les consdidérations topographiques connexes. Il est pourtant incontestable qu'Israël doit faire face à des menaces graves pesant sur a sécurité et celle de ses citoyens" ${ }^{63}$. De todo esto sí que tomaría nota la Corte Suprema de Israel, llegando así a un resultado distinto, y cambiando el trazado de algunos tramos.

Estas mismas dudas o reproches están presentes igualmente en otros autores. Tal es el caso de Djanichid Montaz ${ }^{64}$, Profesor de la Universidad de Teherán, quien critica a la Corte por

Internacional, 2004, pp. 467-491; Pozo Serrano, Pilar.: "La Opinión Consultiva de la CIJ sobre las consecuencias jurídicas de la construcción del muro en el territorio ocupado palestino: problemas de competencia y oportunidad judicial", Anuario de Derecho Internacional, 2004, pp. 493-518.

${ }^{62}$ No han faltado autores que ya han mostrado su preocupación para resolver estas cuestiones, como Good Davis P.: "The Need for Fundamental Change in the Law of Belligerent Occupation", Standford Law Review (1985), pp. 1573-1608; y Scheffer, David.J.: "Beyond Occupation Law", AJIL (2003), pp. 842-860. Sobre esta cuestión, este último autor pone el dedo en la llaga en repetidas ocasiones y algunas como estas que transcribimos a continuación nos parecen interesantes: "Many situations in which armed forces exercice control in foreign territory involve unique elements and circonstances... One possible reason for the reluctance of many states to accept the full de jure application of occupation law to situations in wich they are involved may be a belief, whitter or not justified, that the situation differs significantly from the typical case of occupation", p. 843. Y pensando en las atrocidades existentes, dice lo siguiente: "International society is becoming increasinglty intolerant of atrocity crimes on a scale that imperil whole societies, and of rulers who deny their own peoples typically with repressive measures the right to fair and representative government. The means by wich to address these challenges are not found in occupation law... Perhaps, the time has arrived not only to examine the full scope of occupation law, but also revisit from a contemporary perspective the non-self-governing territories and trusteeship provisions of the UN charter. The goal should be to craft a modern application of these principles, revised to reflect the realities of the twenty-first century, so that the protection or transformation of societies at risk can be achieved withing a realistic and acceptable framework of Law", p. 860.

${ }^{63}$ Rivier, Raphaële : “Conséquences juridiques de l'édification d'un mur...”, op. cit., pp. 329-330.

${ }^{64}$ De este autor, véase: "Israel and the Fourth Geneva Convention: On the ICJ Advisory Opinion Concerning the Separation Barrier", Yearbook of International Humanitarian Law, 2005, pp. 344-355, especialmente 354-355. 
señalar, sin dar mucha justificación a su posicionamiento, que no está convencida de que el trazado elegido por Israel para construir el muro sea necesario para alcanzar sus objetivos de seguridad $^{65}$. Para este autor, esta afirmación no sólo es excesiva, sino que visto desde una cierta retrospectiva, es completamente errónea a la luz de lo que ha representado la valla/muro en esta materia hasta la actualidad, sobre todo en partes de su trazado como ha sido el que está construido entre Belén y Jerusalén. Es más, este autor señala claramente que es preferible seguir la Declaración del Juez Thomas Buergenthal ${ }^{66}$ para darse cuenta de que parte del trazado respondía perfectamente a las condiciones de una seguridad razonable y otras no, mientras que el Juez El Araby va incluso más lejos al indicar en su Opinión individual que la construcción del muro podría estar justificado por razones de seguridad, aunque no la destrucción de la propiedad $^{67}$. Algo similar indica el Juez Kooijmans al reprochar a la Corte no haber sometido la construcción del muro al test de proporcionalidad ${ }^{68}$.

Así pues, casi setenta años después de los Convenios de Ginebra, y casi cincuenta desde los Protocolos, todo apunta a que una mera revisión cosmética no sería suficiente, y que habría que ir, parece, a una buena operación de cirugía para adaptarlo a las nuevas situaciones internacionales, siguiendo así las ideas del precitado autor Michel Veuthey. Este autor presenta, a pesar de sus feroces críticas al sistema humanitario vigente, un espíritu humanitario ejemplar, al recordarnos que cualesquiera que sean la solución y la formulación que finalmente sean retenidas en la elaboración de la nueva codificación, lo esencial es provocar una toma de conciencia de la realidad y de la necesidad del Derecho humanitario: más que las lagunas y las dificultades de los textos, es la ausencia de voluntad política la que por desgracia permite muy a menudo poner el Derecho en contra de la humanidad y la letra contra el espíritu del Derecho humanitario ${ }^{69}$. Los conflictos, y la forma de llevarlos a cabo no solo han evolucionado, sino que se han revolucionado, mientras que el régimen jurídico de Ocupación sigue anclado en el pasado.

\section{El fin de la ocupación}

$\mathrm{Si}$ ver cuando un territorio puede considerarse como ocupado no parece plantear grandes controversias a la luz del Derecho internacional humanitario actual, salvo algún caso específico como es el de los territorios palestinos, al menos teóricamente hablando, establecer el fin de la ocupación es más complejo, sobre todo a la hora de llevarlo a la práctica. Y es que el artículo 6 del Cuarto Convenio de Ginebra, en su párrafo tercero recoge que "en territorio ocupado, la aplicación del convenio terminará un año después del cese general de las ocupaciones militares...". Retiene, pues, un elemento fáctico como para evaluar el comienzo de la ocupación, algo que está presente en el Reglamento de La Haya, como ya hemos apuntado, y que es derecho consuetudinario. Son embargo, el propio Convenio, en ese mismo párrafo indica que “... no obstante, la Potencia Ocupante estará obligada mientras dure la ocupación -si esta Potencia ejerce las funciones de gobierno en el territorio de que se trata- por una serie de disposiciones, pero no por toda la Convención". Esto que dice el Cuarto Convenio de Ginebra es modificado por el artículo 3.6 del Protocolo I adicional a los Convenios de Ginebra, al señalar que, en el caso de los territorios ocupados, la aplicación de los Convenios y del Protocolo cesará al término de la ocupación, salvo en algunas circunstancias recogidas en la misma disposición relativas a las personas cuya liberación definitiva, repatriación o reasentamiento tenga lugar

\footnotetext{
65 Párrafo 137.

66 p. 240 , párrafo 5.

${ }^{67}$ Véase: p. 257, párrafo 3.2.

${ }^{68}$ Opinión individual del Juez Kooijmans, p. 229, párrafo 34.

${ }^{69}$ De este autor, véase : "Guérrilla et Droit Humanitaire", op. cit., Remarque Finale, p. 378.
} 
posteriormente. Es decir que desde el punto de vista convencional el alcance de la ocupación va a depender en buena medida de si las Partes van a estar vinculadas por el Protocolo I o no ${ }^{70}$.

En realidad, este ha sido uno de los argumentos invocados por Israel para negar que de iure fuera una Potencia Ocupante de los territorios palestinos durante todo este tiempo, pues Israel no es Parte en el Protocolo, como ya se ha apuntado. Así las cosas, Israel no se considera vinculado por él, salvo que la disposición sea norma consuetudinaria ${ }^{71}$. Hay que recalcar, sin embargo, que Israel nunca ha invocado este período de un año para desvincularse de sus obligaciones en los territorios palestinos. Pero es que, lo que se olvida en muchos casos, es que el régimen de la "ocupación militar" recogido en el Cuarto Convenio de Ginebra está pensado para ser una fase provisional hasta que las armas decidieran el conflicto, o para transformar el territorio ocupado en otro estatuto a través de las negociaciones, acuerdos de armisticio, etc. ${ }^{72}$. Sin embargo, no es lo mismo una ocupación pasajera o corta, que una prolongada en el tiempo como la de Namibia por Suráfrica, la zona Norte de Chipre por Turquía, y por supuesto la de Israel en los territorios palestinos, aunque se pueden citar otros muchos ejemplos ${ }^{73}$. Podría preguntarse también qué se entiende por "ocupación prolongada". A este respecto, Adam Roberts habla que podría ser una ocupación que va más allá de cinco años y que se extiende por un período en el que las hostilidades se han reducido considerablemente de forma que al final se llega a un período casi completamente pacífico $^{74}$.

A este respecto, conviene resaltar que ni el Derecho convencional ni el consuetudinario distingue entre una ocupación a corto plazo de otra que se dé durante un largo período. Es cierto que algunos órganos de las Naciones Unidas se han referido a los territorios ocupados por Israel en algunas de sus resoluciones recurriendo al término de "prolonged occupation", como por ejemplo el Consejo de Seguridad en su Resolución 471, del 5 de junio de 2001, párrafo 6, en el

\footnotetext{
${ }^{70}$ Kolb, Robert y Vité Silvain : "L'applicabilité ratione temporis du droit de l'occupation de guerre: le debut et la fin de l'occupation", en Chetail, Vicent. (ed.) (2013) : Permanence et mutations du droit des conflits armés, Bruylant, Bruselas, p. 150. Y es que, si bien 172 países han ratificado el Protocolo I, 24 todavía no lo han hecho, entre ellos India, Irán, Israel, Tailandia, Turquía y, sobre todo, Estados Unidos. Francia tan solo lo ha ratificado el 11 de abril de 2001, y conviene resaltar que Palestina lo ha ratificado el 2 de abril de 2014, haciendo una reserva al artículo 90 sobre la Comisión Internacional de Encuesta. Esto no impide decir, sin embargo, a algún autor, que a pesar de que estos países no hayan ratificado este Protocolo, "However there is more tan sufficient proof of these states support for the rule of article 3 (B)", véase Kotroulis, Vaios.: "The Application of International Humanitarian Law and International Human Rights in Situation of Prolonged Occupation: Only a Matter of Time?", Int. Rev. Red.Cross (2012), p. 174.

${ }^{71}$ Conviene apuntar que el Protocolo retoma lo que no retuvo la Conferencia Diplomática de 1949 en relación con el período de un año. Commentaire des Protocoles additionnees du 8 juin 1977 aux Conventions de Genève du 12 août 1949, Nijhoff, Genève 1986, p. 68.

${ }^{72}$ A este respecto, véase : Haggenmacher, Peter : "L'occupation militaire en droit international : Genèse et profil d'une institution juridique", Relations Internationales (1994), pp. 285 y ss.

${ }^{73}$ A este respecto, véase: Roberts, Adam.: "Prolonged Military Occupation: the israelí-occupied territories since 1967", AJIL, 1990, pp. 50 y ss.; y "Decline of illusions. The Status of the Israeli-occupied Territories avec 21 Years", International Affairs, vol. 64 (1988), pp. 345-359. No conviene olvidar tampoco la ocupación de Alemania y la de Japón, la de Austria de 1945 a 1955, etc.

74 “Prolonges military occupation...”, p. 47. Desde esta perspectiva, una prolongada ocupación corre el riesgo de que se deje de considerar el territorio ocupado como si no estuviera sometido al régimen previsto por el Derecho internacional, es decir a una categoría jurídica excepcional como es el régimen de ocupación. A este respecto, el ya citado Adam Roberts ve en esta situación un peligro al señalar lo siguiente: “... The danger in making such a suggestion is that it may seem to imply the further suggestion that those parts of the laws of war that deal with military occupations may not be fully applicable, and that departures from the law may be permissible. These conclusions would pose problems, especially if the applicability of major conventions were put in doubt, if the criteria for permitting departures from the law were vague and subjective, or if it were unclear what bodies have authority to suggest or make departures. However, it may be that departing from occupation law is not the only legal issue to be faced. There may also be some scope for variations within the framework established by existing international law. The lavers of war treaties that govern occupations contain some scope for variations. Ibid, p. 51.
} 
que "reafirma la necesidad imperiosa de poner fin a la prolongada ocupación de los territorios árabes ocupados por Israel desde 1967, incluso Jerusalén"75. Por su parte, Yoram Dinstein define una "ocupación prolongada" tomando como criterio únicamente el tiempo. Desde este prisma va a distinguir entre una "semi-prolonged occupation", cuya duración comprenderá un número de años, en lugar de décadas, y considerando un período que puede ir entre tres o cuatro años desde el comienzo de la ocupación ${ }^{76}$.

Hay que reconocer que hoy en día, la expresión "territorios ocupados" se asocia en general con los territorios que todavía ocupa Israel entre aquellos que ocupó tras la Guerra de los Seis Días, es decir, Cisjordania, el Golán y Jerusalén Este, una vez que ya retrocedió la Península del Sinaí a Egipto. Respecto a Gaza, hay serias controversias sobre si sigue ocupado o no, como veremos más tarde. Por lo tanto, no todos los territorios ocupados en 1967 siguen actualmente ocupados. El Golán y Jerusalén-Este fueron anexionados a Israel en 1980 y en 1981, respectivamente, anexiones que siguen siendo controvertidas. La controversia parece más viva en torno al Golán que en relación con Jerusalén, tras los últimos posicionamientos adoptados en los últimos tiempos por el Presidente estadounidense Trump, que le ha llevado a trasladar incluso la Embajada de los Estados Unidos de Tel Aviv a Jerusalén, acto que empieza a tener algún reconocimiento en otros países. Y es que, además, Jerusalén es para muchos judíos la capital eterna de Israel.

Lo que es cierto es que la ocupación de estos territorios sorprendió bastante a Israel, salvo quizás a Moshé Dayán, que había considerado en algún momento la posibilidad de tomar Cisjordania $^{77}$. Y es que lo primero que intentó el Gobierno de unidad nacional israelí fue alcanzar acuerdos de paz con Egipto y Siria para transferirles los territorios ocupados durante la guerra, mientras que Cisjordania y Gaza se quedaban fuera de ese proyecto. Como indicó Beguín más tarde en relación con estos territorios "se decidió no decidir", debido a que aquí la situación existente anterior a la guerra planteaba muchos problemas para la seguridad de Israel debido a la estrechez del territorio ${ }^{78}$.

Así las cosas, se tuvo que ir pensando en la "ocupación", y a este respecto se adoptó por los comandantes generales de los diversos frentes una ordenanza según la cual se establecían

\footnotetext{
${ }^{75}$ Esta Resolución se adoptó a causa de los atentados llevados a cabo contra los alcaldes de Nablus, Ramallah y Al Bireh, todas ellos en Cisjordania y muy cercanas unas de otras, a causa de los cuales les tuvieron que amputar las piernas a los alcaldes de Nablus y Ramallah, saliendo el de Al Bireh ileso. Estos atentados tuvieron lugar el 2 de junio de 1980 tras el atentado palestino de Hebrón en el que murieron seis soldados israelíes. Pero no fueron los únicos a que se llevaron a cabo esa misma mañana, ya que en el de Hebrón un atentado causó diez heridos.

76 Para más detalles sobre esta cuestión, véase: Dinstein, Yoram: The International Law of Belligerent Occupation..., op. cit., p. 116. Para un estudio sobre este tema, véase: Koutroulis, Vaios (2010): Le debut et la fin de l'application du droit de l'occupation, Paris, Pedone, especialmente pp. 19-94; de este mismo autor, "The Application of International Humanitarian Law...”, op. cit., pp. 168-169. Este autor trae a colación además el Asunto de las Actividades armadas en el territorio del Congo, señalando que a pesar de que la ocupación dura entre cuatro o cinco años, la Corte no habla ni de ocupación semi-prolongada ni de prolongada, ya que para ella es igual el período de tiempo en cuestión, teniéndose que aplicar el Derecho internacional humanitario desde el principio hasta el fin.

${ }^{77}$ Esto es lo que apunta al menos Morris, Benny (2001): Righteaus Victims. A History of the Zionist-Arab conflict 1881-2001, Random House, p. 314. Esto contrasta, sin embargo, con la declaración que hizo al entrar en JerusalénEste tras ser tomada por los paracaidistas israelíes, según la cual lanzó la frase siguiente: "Qué vamos a hacer nosotros ahora con este Vaticano". Bermejo García, Romualdo: El conflicto árabe-israelí en la encrucijada: ¿Es posible la paz?, Pamplona, Eunsa, 2002, p. 45. Hay que recalcar que Moshé Dayán, Ministro de Defensa durante la Guerra de los Seis Días propuso en 1981 devolverlos, y este era uno de los puntos más importantes del partido Télema que acababan de crear. Hay que reconocer sin embargo que fue un líder mejor preparado para la milicia que para la política. No obstante, siempre fue muy respetado y sería considerado como un héroe de guerra y un arquitecto de la paz hasta su muerte el 16 de octubre de 1981.

${ }^{78}$ Bermejo García, Romualdo. y Pozo Serrano, Pilar.: Una tierra, dos Estados: Análisis jurídico-político del conflicto árabe-israelí, Pamplona Eunsa, 2011, pp. 120-122.
} 
Tribunales militares para juzgar a los residentes de las zonas ocupadas por delitos contra la seguridad $^{79}$. Sin embargo, se levantaron voces en Israel en torno al estatuto de Cisjordania y Gaza, según las cuales, estos territorios habían formado parte del Mandato británico en Palestina y que, por tanto, no podían considerarse como territorios ocupados. Esta actitud hizo cambiar de opinión a los mandos militares, borrando de la Orden precitada la alusión al Cuarto Convenio de Ginebra ${ }^{80}$. Fue así como el Gobierno israelí empezó a sostener que el estatuto de ambos territorios no estaba claro, y que la aplicación de dicho Convenio era discutible, aunque decidían en la práctica aplicarlo ${ }^{81}$.

Hechas estas consideraciones, lo primero que hay que resaltar es que habrá fin de la ocupación cuando la Potencia ocupante se retira del territorio bien por propia voluntad o bien porque es obligada a ello. Es decir, no hay efectividad sobre el terreno, y por lo tanto pierde el control. Si hay revueltas, aunque estas sean importantes, o combates en la zona, esto no quiere decir que se ha puesto fin a la ocupación ${ }^{82}$.

Esto fue lo que ocurrió en realidad en el conflicto iraquí en varias ocasiones ${ }^{83}$. Y es que hay que reconocer que, a menudo, en muchas operaciones militares se cometen errores tanto a nivel táctico como estratégico. Aunque ambos pueden estar interrelacionados en algún caso, en el caso de los errores estratégicos, como señala el Major Matthew R. Hover, las consecuencias pueden ser catastróficas, como ocurrió con Alemania en la Segunda Guerra Mundial ${ }^{84}$. Este autor señala que las fases que encierran normalmente una operación militar son seis, que son las siguientes: “....Shape (Phase 0), Deter (Phase I), Seize the Iniciative (Pase II), Dominante (Phase III), Stabilize (Phase VI), and Enable Civil Authority (Phase V)". Es más, nos indica que la Ocupación está comprendida en la fase IV, es decir la de estabilización, pero que a falta de un plan operativo tanto a nivel táctico como estratégico, se condenó la ejecución táctica de la ocupación a un fracaso desde el principio. Es más, los militares estadounidenses no quisieron participar en operaciones de estabilización, queriendo evitar así los costes que trae consigo un proyecto de "nation building", siguiendo así la doctrina del Secretario de Defensa Donald Rumsfeld, que ya antes de la invasión de Irak dijo que "We are not interested in nation building. This is nor what we do. This is not what we are goint to do" 85 .

Como pone de relieve Adam Roberts, "The fact that there was an occupation in Iraq was formaly affirmed in UN Security Council Resolution $1483 \ldots$, wich recognised the specific

\footnotetext{
79 Security Provisions Order (West Bank), 1967. Proclamations, Orders and APPointenents of West Bank Command 5.

80 Security Provisions Order (West Bank) (Amenament No 9) (Order No 144), 22 october 1967, en: Proclamations, Orders and Appointments of West Bank Command 303.

${ }^{81}$ Para más detalle, véase el interesante estudio sobre estos territorios de Kretzmer, D.: “The Law of Belligerent Occupation in the Supreme Court of Israel", Int. Rew. Red. Cross (2012), pp. 208-211.

${ }^{82}$ Como señala el Manual Militar británico, "Occupation does not become invalid because some of the in- habitants are in state of rebellion, or through occasional successes of the guerrilla bands or 'resistance' fighters. Even a temporally successful rebellion is not sufficient to interrupt or terminate occupation, provided that tha authority of the legitimate government is not effectively re-established and that the occupant suppresses the rebellion at once". UK Manual of the Law of Armed Conflicts..., op. cit., párrafo 509. Algo parecido recoge el Army's Fied Manual 27-10, cuando señala que "the mere existence of a fort or defended área withim the occupied district, provided the fort or defended area is under attack, does no render the occupation of the remainder of the district inneffective".. Sección 356.

${ }^{83}$ Thürer, Daniel y McLaren, Malcom: "Just Post Bellum, in Irak: A Challenge to the Applicability and Relevance of International Humanitarian Law", en Dinke Klaus et alia (2005): Weltinnenrecht, Liber Amicorum Jost Delbiück, Berlín, Duncker and Humblod, p. 773. Véase también sobre la ocupación de Irak. Venet, Olivia : "L'occupation du territoire irakien et l'intervention du Conseil de sécurité : conséquences sur les pouvoirs reglementaires de la puissance ocupante et réflexions sur les modes d'action choisies", RBDI (2006), pp. $274-299$. ${ }^{84}$ Hove, Matthew R.: "The Occupation of Irak: A Military Perspective on Lessons Lerned", Int.Rev. Red. Cross (2012), p. 340.

${ }^{85} \mathrm{Ibid}$, p. 340-341. Esto contrasta evidentemente con lo que se hizo con Alemania.
} 
authorities, responsibilities, and obligations under applicable international law of these States as occupying power under unified command (The "Authority"). This UN Resolution did not create the occupation: it simply recognized that it already existed... The temporary and transformative character of the occupation was reflected in several provisions, including one supporting the formation of an iraqi administration... until an internationally recognized, representative government is stablished by the people of Iraq and assumes the responsibility of the Authority" $" 86$.

Hay que remarcar, sin embargo, que la Resolución 1483, que se refiere a los Estados Unidos y al Reino Unido como "Potencias Ocupantes", no aclara sin embargo la cuestión de saber qué ocurría con el resto de países que como España, Italia, Japón o Polonia, por ejemplo, tenían tropas desplegadas en Irak. Lo que indica a este respecto es que "señalando además que hay Estados que no son Potencias Ocupantes están realizando tareas o quizás lo hagan en el futuro, en el marco de la Autoridad". Todo parece indicar que lo que se pretende con esta observación es exculpar de las responsabilidades de las dos Potencias Ocupantes reconocidas a todos estos países que ayudaban en el mantenimiento de la seguridad en Irak, pero esto cambia a partir del 1 de julio de 2004, por lo que a partir de esta fecha estarían actuando de facto como Potencias Ocupantes, ya que la Resolución 1546 recoge en su párrafo 4 "el establecimiento de un Gobierno provisional soberano de Irak que asumirá las funciones y atribuciones de Gobierno para el 30 de junio de 2004" ${ }^{\prime 7}$. Cabe, sin embargo, poner de relieve que esa presencia es acogida con satisfacción "en el preámbulo de esta resolución, y se podría interpretar también que su presencia se debe a un consentimiento del nuevo Gobierno iraquí en que la presencia militar de estos Estados continúe. Dicho esto, lo cierto es que la Resolución no despeja las dudas que se pueden suscitar al respecto, ya que, aunque fueron sin ser consideradas como Potencias Ocupantes, a partir del 1 de julio sus funciones y comportamiento son los típicos de las dos Potencias reconocidas como "Ocupantes", es decir los Estados Unidos y el Reino Unido. Por lo tanto, cómo se ha señalado "... The rules laid down in international Humanitarian law, and most particularly in the 1949 Geneva Conventions, continue to be applicable to iraquí government forces and to all those who serve in the multinational force in Iraq" $" 88$.

En realidad, toda esta historia de Irak nos muestra un ejemplo relativamente reciente en donde la "efectividad" sigue estando presente. Y es que la Resolución 1546 no puede poner fin a la Ocupación, ya que el control efectivo sobre el territorio a 30 de junio de 2004 no estaba en manos del Gobierno iraquí. Poner Gobiernos marionetas sin que puedan ejercer un control efectivo sobre el territorio no exculpan de su responsabilidad a las Potencias que de facto ejercen el control efectivo sobre el territorio ${ }^{89}$.

Dicho esto, hay que reconocer, además, que no siempre una evaluación sobre lo que ocurre en el terreno es tan clara como se piensa en ocasiones, ni tan fácil a la hora de saber el

\footnotetext{
${ }^{86}$ De este autor, véase: "The End of Occupation: Irak 2004", International and Comparative Law Quarterly (2005), p. 32.

${ }^{87}$ Estos comentarios no son aplicables ya a España, pues como se sabe, a raíz de los atentados del 14 de marzo en España, atribuidos por algunos políticos españoles al apoyo prestado por el Gobierno de José María Aznar a la Guerra de Irak, y que en gran medida trajo consigo el cambio de Gobierno de Aznar a Zapatero, este decidió, un día más tarde de tomar posesión de su cargo, es decir, el 18 de abril de 2004, retirar las tropas españolas de Irak, decisión que no fue muy bien comprendida, ni incluso digerida, y que tendría consecuencias en la confianza que nuestros aliados podían tener en España. Los últimos soldados cruzarían la frontera entre Irak y Kuwait el 21 de mayo.

${ }^{88}$ Roberts, Adam.: "The End of Occupation...", op. cit., pp. 48.

${ }^{89}$ Dörmann, Kunt. y Colassis, Laurent.: "International Humanitarian Law in the Irak Conflict", GYIL (2004), p. 309, en donde se señala lo siguiente: "Not every transfer of authority to a local government and an ensuing consent to the presence of troops necessarily leads to an end of occupation. The devolution of governmental authority to a national government must be sufficiently effective... The reason for this is evident. Situations must be avoided where the protection to be granted to persons and property under the law of occupation can be circunvented"
} 
momento preciso en el que una Potencia Ocupante se retira del terreno controlado ${ }^{90} \mathrm{y}$ pierde su efectividad. En algunos casos, este se negocia, dando así lugar a una retirada programada tanto en el tiempo como en el espacio. En estos casos, el control del territorio va a pasar, tal y como se ha negociado, de la Potencia Ocupante a la Potencia cuyo territorio estaba ocupado. Sin embargo, en otros casos es el Ocupante el que expresa su voluntad unilateralmente de retirar del territorio, como ha sido el caso de Israel en el Sur del Líbano en el año 2000, o posteriormente en la Franja de Gaza, como veremos más tarde.

En el caso de la retirada de Israel del Líbano, las fuerzas israelíes se retiraron de la zona de seguridad del Sur del Líbano, tras veintidós años de ocupación. Para cumplir con este objetivo, el Consejo de Seguridad decidió que las Naciones Unidas, y sobre todo su Secretaría General, establecieran los requisitos para llevar a cabo esta retirada y confirmar así que se había llevado a cabo. El 16 de junio del 2000, un Informe del Secretario General al Consejo de Seguridad de las Naciones Unidas confirmaba que las fuerzas armadas israelíes se habían retirado de la zona tal y como estaba previsto en la Resolución 425 del Consejo de Seguridad, del 19 de marzo de $1978^{91}$. Posteriormente, en la Resolución 427 del 3 de mayo el Consejo tomo nota en su párrafo 2 del "retiro de las fuerzas israelíes que se ha llevado a cabo hasta hora", pero lo cierto es que nunca se decidió después a calificar que había habido retirada y por lo tanto el fin de la ocupación. No obstante, como Israel trasfirió a Líbano el territorio, a falta de un tratado de paz entre las Partes, y por ende también la seguridad y el control, esto bastó para poner fin a la ocupación. Todo esto dejaba claro que Israel de facto ya no controlaba el territorio y dejaba de tener cualquier responsabilidad sobre la población de la zona. El último soldado israelí salió del territorio libanés a las 03:45 GMT del 24 de mayo de 2000, poniendo así fin a la ocupación de un territorio que a medida que las tropas israelíes la iban abandonando, era ocupado no por las fuerzas armadas libanesas, sino por las milicias de Hezbolá ${ }^{92}$. Por lo tanto, Israel completó su retirada seis semanas antes de lo que estaba programado, cosa pensada pero no esperada por los libaneses.

En otros casos, el Ocupante se retira del territorio ocupado mediante un Tratado internacional con el Estado ocupado bien sea para retirarse sin más, bien sea en unas determinadas condiciones. Esto fue lo que sucedió con el Tratado de Paz del 28 de abril de 1952, fecha en la que entró en vigor, en Japón, que puso fin a la ocupación militar estadounidense, al mismo tiempo que entraba en vigor un Tratado de Seguridad entre ambos países que preveía la continuidad de la presencia militar estadounidense en el país ${ }^{93}$. Algo similar ocurrió con Alemania al entrar en vigor el 5 de mayo de 1955 una seria de Tratados, uno de los cuales preveía el fin de la ocupación de los Estados Unidos, Francia y el Reino Unido, otro destinado a que las fuerzas de estos países continuaran con su presencia en la que era la ya la República Federal Alemana, y otro para que este país entrara en la Unión Europea Occidental y en la OTAN. Parecido fue lo que se hizo con la Alemania Oriental, es decir, la

\footnotetext{
${ }^{90}$ Este aspecto de la efectividad es importante, pues puede ocurrir que esa efectividad la Potencia Ocupante la haya perdido sin que forzosamente implique que todas sus fuerzas ya se hayan retirado. Esto suele ocurrir cuando se lleva a cabo entre la Potencia Ocupada y la Parte que tiene territorio ocupados negocian un Acuerdo de retirada como ocurrió entre Israel y Egipto con el Acuerdo de Camp David de 1979, aspecto que abordamos infra.

${ }^{91}$ Esta Resolución “decide” en su párrafo 3 que, a la luz de la solicitud del Gobierno de Líbano hay que "establecer inmediatamente, bajo su autoridad, una fuerza provisional de las Naciones Unidas para el Líbano meridional con el fin de confirmar el retiro de las fuerzas israelíes, restaurar la paz y la seguridad internacionales y ayudar al Gobierno del Líbano a asegurar el restablecimiento de su autoridad efectiva en la zona...”. Es más, el párrafo 4 pide al Secretario General que informe al Consejo dentro de las próximas veinticuatro horas sobre la aplicación de la presente Resolución.

${ }^{92}$ La retirada se hizo sin ninguna baja del lado israelí, y fue considerada como un éxito total. Sin embargo, dejaban desamparados a las milicias del denominado "Ejército del Sur del Líbano", y por ello el Gobierno israelí ofreció asilo a más de 5000 libaneses, ofreciéndoles vivir en Israel, regresar al Líbano o irse a un país tercero.

${ }^{93}$ Ambos tratados se firmaron ya el 8 de septiembre de 1951.
} 
antigua República Democrática Alemana mediante la Declaración del Gobierno soviético del 25 de marzo de 1954. Se quedaba fuera de estos Tratados Berlín, que quedó bajo la ocupación de las Cuatro Potencias Ocupantes hasta el Tratado del 3 de septiembre de 1971, sin que figurara en el Tratado ni la palabra "ocupación" ni la de "Berlín"94.

Otro caso más reciente y quizás más claro, es el Tratado de paz israelo-egipcio del 26 de marzo de 1979, firmado en Washington. Este Tratado consta de nueve artículos, un Anexo sobre la retirada israelí, dos Protocolos en materia de seguridad, un Protocolo sobre las relaciones entre las Partes. Este Tratado pone así fin al estado de guerra entre las Partes, prevé la completa retirada del Sinaí por parte de Israel y la plena recuperación del ejercicio de la soberanía por parte de Egipto. Una vez efectuada la primera fase de la retirada israelí, se debían establecer relaciones diplomáticas entre ambos Estados. Por lo tanto, el elemento central del Acuerdo sería paz por retrocesión de territorios y reconocimiento de Israel ${ }^{95}$. Además de este Tratado en Camp David se celebró también otro entre Israel y los Estados Unidos que recogía los compromisos de los Estados Unidos hacia Israel en caso de violación del Tratado y en materia de ayuda militar.

Pero puede ocurrir también que se ponga fin a la ocupación sin que se retiren las tropas de la Potencia Ocupante siempre que la Potencia ocupada lo consienta evidentemente. Ni que decir tiene que el consentimiento en cuestión tiene que ser auténtico y expresamente aceptado ${ }^{96}$. Los casos de Alemania y de Japón, que ya hemos comentado son un buen ejemplo de ello.

\section{El caso especial de Gaza: algunas reflexiones}

La denominada Desconexión de la Franja de Gaza viene ocupando a la doctrina desde que se empezó a fraguar en Israel, pero sobre todo desde el 12 de septiembre de 2004, fecha en la que las últimas tropas israelíes abandonan la zona, a las 7 de la mañana, que venían ocupando desde 1967. Desde entonces, este tema viene suscitando acerbas polémicas en la doctrina que se ocupa de estas cuestiones del Derecho internacional humanitario: algunos con pasión e inteligencia, y otros sobre todo más con pasión. El tiempo, sin embargo, ha venido poniendo a casi todos en su sitio, sobre todo tras hacerse en la Franja de Gaza con el poder Hamás en junio de 2007. Este hecho iba a trastocar profundamente no solo a la Autoridad Palestina sino también al proceso negociador israelo-palestino. Desde entonces Hamás sigue en el poder, pero vayamos por partes.

Desde el año 1987, año en el que se inicia la Primera Intifada ${ }^{97}$, pero sobre todo desde el año 2000, año en el que se inicia en septiembre la Segunda Intifada, Israel tiene que hacer

\footnotetext{
${ }^{94}$ Para más detalles sobre estos Tratados, véase: Roberts, Adam.: "The End of Occupation: Irak 2004", International and Comparative Law Quarterly (2005), pp. 27-48, p. 29.

${ }^{95}$ Conviene tener presente también que un aspecto importante previsto en este Tratado es la desmilitarización del Sinaí. La primera fase de la retirada se completó el 25 de enero de 1980, y el 25 de abril de 1982, las fuerzas israelíes se habían replegado de forma efectiva a la frontera internacional de 1967. Surgiría después el Asunto de Taba que un Tribunal arbitral otorgaría a Egipto. A este respecto, véase Quand, William B.: Peace Process. American Diplomacy and the Arab-Israeli Conflict since 1967, 3rd edition, Brooking Institution Press, Washington D.C., 2005, pp. 235-242.

${ }^{96}$ A este respecto, Kolb, Robert y Vité, Silvain. : 'L'applicabilité ratione temporis du droit de l'occupation de guerre: le debut et la fin de l'occupation", en Chetail, Vicent. (ed.) (2013) : Permanence et mutations du droit des conflits armés, Bruylant, Bruselas, p. 135.

${ }^{97}$ Esta Primera Intifada sorprendió considerablemente a las autoridades israelíes, que no entendían muy bien las causas de estas revueltas, pues el desarrollo económico palestino fue muy alto en las primeras décadas de ocupación. No obstante, el fracaso de unas negociaciones diplomáticas que se habían iniciado en Londres entre israelíes y palestinos causaron una gran decepción de ahí que haya autores que defiendan "que la Intifada no fue solo una rebelión contra la ocupación israelí, sino también contra la OLP”. Véase: Bermejo García, Romualdo y Pozo Serrano, Pilar: Una tierra, dos Estados...", op. cit., p. 184. Esta Intifada se denominó también "la de las
} 
frente en los territorios palestinos a una ola de violencia que iba a desencadenar no solo revueltas y manifestaciones por parte de la población palestina, sino también numerosos atentados terroristas, que llegaron a causar unos 1100 muertos en Israel y millares de heridos ${ }^{98}$. Si se comparan estas cifras con las que han sufrido los países occidentales, la diferencia es enorme, a causa de la pequeña población de Israel en el año 2000, que era de 6,289 millones. Si decimos esto es para demostrar que los heridos y muertos en este conflicto no están solo de un lado.

\subsection{La desconexión de Gaza}

La desconexión israelí de la Franja de Gaza no fue un acto irreflexivo propuesto por algunos militares o políticos israelíes, sino que el que lo propuso fue el por entonces Primer Ministro Ariel Sharon, un hombre que combatió en todas las guerras de Israel que habían tenido lugar hasta entonces. El Plan fue presentado el 18 de diciembre de 2003, en un discurso ante la Conferencia de Herzlíya, lugar conocido por sus famosos encuentros en los que participan no solo líderes políticos israelíes, sino también internacionales. En su discurso, recalcó que tanto los israelíes como los palestinos habían aprobado la "Hoja de Ruta" como un instrumento para alcanzar la paz. Por eso, recalcó que "una implementación total y genuina del programa es la mejor forma de alcanzar una paz verdadera... Estamos dispuestos a avanzar hacia su implementación: dos Estados, Israel y un Estado palestino, que vivan uno junto a otro en tranquilidad, seguridad y paz"99. Pero Sharon va más lejos y advierte que en un escenario futuro, es decir, en el marco de un acuerdo final, “... Israel no permanecerá en todos los lugares en los que se encuentra hoy", e invita a las autoridades palestinas a cumplir con sus obligaciones asumidas de erradicar los grupos terroristas y crear una sociedad en cuyo marco se combata la violencia y se respete la ley. No deja a salvo a Yasser Arafat, a quien reprocha su pasividad ante los brutales ataques terroristas que se habían cometido y que obligaron a Sharon a desencadenar la famosa Operación "Escudo Defensivo" entre los meses de marzo y abril de $2002^{100}$.

Posteriormente, el Plan de Desconexión propuesto por Ariel Sharon sería aprobado por el Gobierno israelí el 6 de junio de $2004^{101}$, y por la Knéset el 25 de octubre, incluido

piedras, pues era como hostigaban los grupos palestinos a las fuerzas israelíes. Ver también, Ben-Ami, S.: Cicatrices de guerra, heridas de paz: la tragedia árabe-israelí, Ediciones B. Barcelona, 2006, pp. 231-232.

${ }^{98}$ El estallido de la Segunda Intifada tuvo lugar a raíz de la visita de Ariel Sharon el 28 de septiembre de 2000 a la Explanada de las Mezquitas, o el Monte del Templo para los judíos, custodiado por 1200 policías, y acompañado por una comitiva de invitados como Moshe Arens, Nomi Blumental o Yeoshua Maza. Esta visita suscitaría una aireada protesta de cientos de palestinos que le estaban esperando, originándose una batalla campal hasta que Ariel Sharon se retiró. La visita contaba con la autorización del entonces Primer Ministro Ehud Barak, y fue vista como una provocación por parte de los palestinos. Schlonimsky, I.: "Con las piedras, con la prensa y con la red. Sin guerra, pero luchando por todos los frentes”, Línea Directa con Israel y Medio Oriente, 11 de noviembre 2000, p. 25. Algunos medios de comunicación occidentales veían en esta Intifada un medio de presión con el fin de alcanzar una verdadera paz. Ver, por ejemplo, Gresh, Alain.: "Intifada para una verdadera paz", Le Monde Diplomatique, diciembre, 2000, pp. 10-11.

${ }^{99}$ A este respecto, ver el texto en: El Plan de Desconexión. Reanudación del proceso de paz israelí, Ministerio de Relaciones Exteriores, Jerusalén, abril 2005, pp. 21-24.

${ }^{100}$ El atentado que desencadenó la Operación fue la matanza en el hotel Park de Netanya de 30 personas el 27 de marzo de 2002, desencadenando la Operación dos días más tarde, es decir, el 29 de marzo. Durante esta Operación tendría lugar la famosa batalla de Jenín. Al final de la Operación el 3 de mayo, los objetivos propuestos fueron alcanzados, al cesar los disparos desde Belén, territorio palestino, contra el barrio de Gilo, de Jerusalén, así como el cese de ataques palestinos. Es más, lo más visible sería la destrucción parcial del Palacio de la Mukataa, en Ramalla, considerado como un símbolo de la Autoridad Palesdtina, en donde se alojaba Yasser Arafat.

${ }^{101}$ Para ver la Resolución del Gabinete del 6 de junio referente al Plan de desconexión, véase El Plan de Desconexión..., op. cit., pp. 25-32. Para el texto inglés de esta Resolución, véase The Cabinet Resolution. Regarding the Disengagement Plan, 6 june 2004 (as published by the Prime Minister's Office) Addendum A Revised Disengagement Plan- Main Principles, en 
Netanyahu, cuando en realidad se oponía a la evacuación. Por eso sus seguidores diputados se opusieron $^{102}$. En el Parlamento israelí Sharon haría un gran esfuerzo para convencer a los diputados, aludiendo a su trayectoria militar impecable reprobando al mismo tiempo a Arafat de no haber encontrado en él un interlocutor válido para alcanzar la paz ${ }^{103}$. Con estos planteamientos, la sociedad israelí y los 8000 colonos allí presentes fueron comprendiendo y digiriendo la acción, e incluso los propios palestinos. En realidad todos comprendían el alcance de la acción propuesta, y todos pensaban que abandonaban de facto y de iure el territorio. Este espíritu estuvo presente igualmente en la Cumbre de Sharm El-Sheik del 8 de febrero de 2005 entre el Presidente de la Autoridad Palestina, Abu Mazen y Sharon ${ }^{104}$.

Así las cosas, solo quedaba ya hacer efectiva la operación de evacuación, acción arriesgada, ya que la desconexión fue considerada en general por los 8000 colonos presentes en Gaza, así como por otros grupos más radicales, como una traición de Sharon, a quien consideraban precisamente como uno de los artífices de los asentamientos. No obstante, todo estaba ya dispuesto para llevar a cabo la operación, en la que participaron unos 55.000 soldados y policías, iniciándose el 16 de agosto de 2005 , y poniéndola fín el 23 de agosto ${ }^{105}$. Los últimos soldados israelíes abandonarían el territorio el 12 de septiembre a las 7 de la mañana poniendo así fin a la prolongada presencia militar de 38 años en este territorio ${ }^{106}$. Al mismo tiempo, el General Kochavi, Comandante de las tropas en Gaza, dejó muy claro el alcance de la retirada, señalando "que la responsabilidad de lo que suceda dentro a partir de ese momento corresponde a la Autoridad Palestina". Esta sería confirmada horas después por el Comandante General del Tsahal en el Sur, el General Dan Harel, quien promulgó un decreto declarando el fin de la ocupación militar, derogando así el adoptado el 6 de junio de 1967, que había establecido el régimen de ocupación en la Franja de Gaza ${ }^{107}$.

http://www.mfa.gov.il/MFA/ForeignPolicy/Peace/MFADocuments/Pages/Revised\%20Disengagement\%20Plan \%206-June_2004.aspx .

${ }^{102}$ Netanyahu mostraría después su disconformidad con la medida al dimitir de su puesto de ministro justo antes de la evacuación.

${ }^{103}$ Claras son sus palabras cuando dice lo siguiente: "habiendo combatido en todas las guerras de Israel y habiendo aprendido de mi experiencia personal que sin una fuerza apropiada no tenemos posibilidad de sobrevivir en esta región que no demuestra compasión hacia los débiles, he aprendido también por experiencia propia que la espada solo no podrá resolver esta amarga disputa en esta tierra". Véase: El Plan de Desconexión..., op. cit., p. 34. Para el texto inglés de la aprobación del Plan de Desconexión en la Kenéset,. Addendum A, Revised Disengagement Plan, Main Principles, en

http://www.enfa.gov.il/MFA/Peace+Process/Reference+documents/Revised+Disengagement+Plan+6-June2004.htm.

${ }^{104}$ En esta Cumbre, Israel dejó claro que no deseaba continuar gobernado al pueblo palestino, pero que los palestinos deben abandonar sueños irreales. Ibid, p. 39.

105 A este respecto, Bubinsky, A.: "La desconexión le puede costar el puesto a Sharon", Línea Directa con Israel y Medio Oriente, septiembre de 2005, pp. 9-10.

106 Shanny, Yuval.: "Faraway, so close: The Legal Status of Gaza after Israel's Disengagement", Yearbook of International Humanitarian Law 2005, p. 369.

${ }^{107} \mathrm{Ibid}$. A este respecto, el portavoz de las fuerzas armadas israelíes hizo una Declaración que con el título "Exit of IDF Forces from the Gaza Strip completed", recoge el texto del decreto del General Dan Harel, que es el siguiente: "Tonight, September 12, 2005 the head of the Southern Command, Maj. Gen. Dan Harel signed a declaration stating the end of military rule in the Gaza Strip. This follows the evacuation of all IDF forces from the region and the handing over of control of the region to the Palestinian Authority; in accordance with the decision of the Israeli government. This declaration annuls, the declaration signed June 6, 1967 by the former Head of the South herm Command, Maj. Gen. Yishayahu Gavish declaring the start of military rule in the area. This is the final legislative act taken by an IDF commander in the Gaza Strip after 38 years of IDF presence in the region",en

www.mfa.gov.il/mfa/pressroom/2005/pages/exit $\% 200 \% 20 \mathrm{idf} \% 20$ forces $\% 20$ from $\%$ the $\% 20$ gaza $\% 20$ strip $\% 20$ co mpleted\%2012-sept-2005.a 
El Plan de Desconexión comprendía además un acuerdo entre Israel y Egipto para que fuerzas de este último país suplantasen a las fuerzas israelíes en el denominado "Corredor Filadelfia", corredor que era utilizado por las organizaciones terroristas palestinas para el contrabando de armas. El estatuto jurídico de este Acuerdo, firmado por mandos militares de ambos países se vinculó al ya mencionado Tratado de Paz que se firmó entre ambos países en 1979, y por lo tanto se trata de un Protocolo militar al mencionado Tratado ${ }^{108}$. Es más, en noviembre de 2005, se aprobó el envío a la zona de una misión de observadores de la Unión Europea de unos 70 agentes de seguridad y de aduanas para controlar la zona. Por último, hay que poner de relieve un hecho no menos importante, y es que el Plan de Desconexión, una vez terminado, la policía palestina empezó a ocupar la zona dentro de un marco negociado y preestablecido con las autoridades israelíes, aspecto que tiene su relevancia a nivel jurídico y político ${ }^{109}$.

Desde esta perspectiva, todo parece indicar que tanto el tenor de los instrumentos jurídicos adoptados para llevar a cabo la Desconexión de la Banda de Gaza como su espíritu dejan ver claramente que la voluntad de las autoridades israelíes era abandonar este territorio con todas sus consecuencias. Dicho esto, y como ya hemos apuntado, el hecho de que una Potencia Ocupante diga que no lo es, no es suficiente para poder afirmar que ha dejado de serlo, estando así obligados a llevar a cabo un examen fáctico para saber si Israel controla de hecho y de forma efectiva este territorio o no. Y es aquí donde la doctrina se ha dividido entre los que sostienen que Israel sigue siendo al fin y al cabo Potencia Ocupante, y entre aquellos que defienden la tesis según la cual Israel ya no es Potencia Ocupante desde el 12 de septiembre de 2005. Conviene poner de relieve que muchos de los que sostienen que Israel sigue siendo Potencia Ocupante no abordan con seriedad la llegada al poder de Hamás en la Banda de Gaza tras las elecciones palestinas del 26 de junio de 2006, un hecho que a nuestro entender es sumamente importante ${ }^{110}$.

\section{2 ¿Continúa siendo Israel Potencia Ocupante en la Franja de Gaza?}

Lo primero que conviene apuntar es que, a pesar de haberse llevado a cabo la Desconexión, la paz no llegaría a la zona, al interpretar los grupos radicales palestinos esta retirada como un signo de debilidad, siguiendo así casi los mismos parámetros que ocurrieron con la retirada del Sur del Líbano del año 2000. Desde este prisma, estos grupos radicales, que reinaban por doquier en la zona, volvieron a reiniciar los ataques no ya contra los asentamientos, que fueron destruidos por Israel, sino contra el Sur de Israel, lo que traería consigo las tres guerras que han tenido lugar desde entonces hasta ahora, dejando al margen otras batallas menores.

Dicho esto, el debate en torno a la cuestión de saber si Israel sigue siendo Potencia Ocupante o no va en dos direcciones distintas, y ambas se centran en la cuestión de saber si de facto, Israel controla el territorio de la Franja de Gaza, y si además, está en condiciones de ejercerlo, tal y como prevé el artículo 42, párrafo 2 del Reglamento de La Haya, como ya se ha apuntado. Desde este prisma, los autores que defienden la tesis positiva, es decir que Israel sigue siendo Potencia Ocupante, sostienen que en el Plan de Desconexión ha conservado una

\footnotetext{
108 Este Protocolo suscitó una cierta preocupación en Israel, ya que la cuestión era saber si este Protocolo modificaba o no el Tratado de Paz de 1979, que prevé para la Península del Sinaí la desmilitarización. A este respecto, la respuesta que dio el por entonces Ministro de Defensa, Saúl Mofaz, despejó las dudas señalando que no introducía ninguna modificación al Tratado, ya que las fuerzas egipcias que debían controlar el corredor pertenecían a la gendarmería y no a las fuerzas armadas. A este respecto, ver "Egipto controlará la frontera en Gaza", Línea Directa con Israel y Medio Oriente, septiembre 2005, p. 11.

${ }^{109}$ Conviene apuntar que este Plan de Desconexión comprendía también la evaluación de algunos asentamientos del norte de Cisjordania.

${ }^{110}$ Para un análisis de estas posiciones véase los artículos de Alvarez-Ossorio, Ignacio.; Levy, Gideo.; Bishara, Marwan.; Hadas Samuel y Harel, Victor.: Política Exterior, vol. 20, nº 110 (marzo/abril 2006), pp. 33-68. Agha, Hussein y Malley, Robert H.: "Elecciones de alto riesgo en Oriente Próximo", Le Monde Diplomatique, edición española, enero 2006, p. 9.
} 
serie de facultades como el control de las fronteras terrestres, marítimas y aéreas. Se invoca también que controla el paso de mercancías a la Franja de Gaza, incluyendo, se comenta, el paso de Rafa en la frontera entre Gaza y Egipto, así como el registro de la población palestina, controlando quién va a ese territorio y qué es lo que van a hacer. Sin embargo, el elemento que en nuestra opinión podría tener más peso en esta tesis es el hecho que Israel, a pesar de que no tiene ya tropas en la Franja de Gaza, sí que las tiene en su proximidad, pudiendo, si se da el caso, intervenir militarmente en la zona. Estos planteamientos que analizan los observadores que defienden la tesis positiva se encuentran recogidos en un documento que las autoridades palestinas sacaron a la luz sosteniendo que la ocupación continuaba a pesar de la desconexión ${ }^{111}$.

Esta tesis ha tenido una cierta buena acogida en algunos autores y en algunas organizaciones internacionales. Entre los primeros, cabe citar al Profesor de la Universidad de Bir Zeit, en Ramalla, Mustafa Mari, que categóricamente afirma que Israel sigue siendo Potencia Ocupante:

"The above makes clear that the universally accepted interpretation of relevant provisions of applicable international humanitarian law is that occupation is a matter of both fact and law, and that the ability of a Power to exercise effective control in enemy territory plays a key role in deciding on the status of a Power with respect to enemy territory. Facts on the ground both immediately following the disengagement in 2005, and more recently since early 2006 leaven no room for questioning the status of Israel in the Gaza Strip: it remains the Occupying Power"

Esta misma opinión ha defendido el Centro Gisha en un desarrollado estudio sobre la Franja de Gaza en el que considera a Israel como Potencia Ocupante, y al mismo tiempo violando, por ende, el Derecho internacional humanitario y los Derechos humanos ${ }^{112}$. Este pronunciamiento lo comparten también asociaciones y centros de investigación que apoyan tradicionalmente las tesis palestinas, aunque algunos análisis sean más matizados que otros.

Sin embargo, hay autores que, sin rechazar esta tesis, se muestran un poco confusos, conscientes de que no todo les cuadra a la hora de considerar a Israel como Potencia Ocupante. Tal es el caso de Nicholas Stephanopoulos, que a este respecto señala lo siguiente:

"But while Israel is no longer responsible for the day-to-day administration of Gaza, it retains a good deal of control over the territory... Israel has argued that thanks to its

\footnotetext{
${ }^{111}$ A este respecto, el "PLO Negociations Affairs Departement", ya plasmó su posición de que la ocupación continuaba en los términos siguientes: "Under the 'Disengagement' Plan, Gazans will still be subjected to the effective control of the Israeli military. Although Israel will supposedly remove its permanent military presence, Israeli forces will retain the ability and right to enter the Gaza Strip at will. Further, Israel will retain control over Gaza's airspace, sea shore, and borders. Under the Plan, Israel will unilaterally control whether or not Gaza opens a seaport or an airport. Additionally, Israel will control all border crossings, including Gaza's border with Egypt. And Israel will 'continue its military activity along the Gaza Strip's coastline'. Taken together, these powers mean that all goods and people entering or leaving Gaza will be subject to Israeli control. Finally, Israel will prevent Gazans from engaging in international relations. Accordingly, if it enacts the 'Disengagement' Plan as envisaged, Israel will effectively control Gaza - administratively and militarily. Therefore, Israel will remain the Occupying Power of the Gaza Strip". PLO Negotiation Affairs Department: “The Israel 'disengagement' plan: Gaza still occupied" (September2005), en www.nad-plo.org/inner.phjp?view=disengagement_Fact_GAZA\%20STILL\%20OCCUPIED

Es más, esto mismo ya lo dijo en octubre de 2004, antes de la retirada de las tropas. Véase: "The Israelí 'Disengagement' Plan: Gaza still Occupied", Sección II, en https:/electronicintifada.net/content/israelidisengagement-plan-gaza-still-occupied/5254.

${ }^{112}$ A este respecto GISHA: Scale of Control: Israel's Continued Responsability in the Gaza Stript, November 2011, especialmente el Capítulo I, pp. 12-25, que trata del control de facto de la zona, y el Capítulo 5, pp. 62 y ss., relacionado con la responsabilidad de las autoridades palestinas a quien considera como actores no estatales, pero con ciertas obligaciones internacionales.
} 
pullout, it is no longer the occupying power in Gaza and thus has no legal duties whatsoever. This Recent Developments contends to the contrary, that Israel still occupies Gaza for two reasons: first, because it retains effective control over the territory, and second, because agreements between Israel and the Palestinian Authority (PA) prohibit unilateral changes to the legal status of Gaza and the West Bank. Moreover, even if Gaza is no longer considered to be occupied, Israel continues to bear legal obligations to the territory under both international law and the IsraelPA accords" $" 113$

Respecto a los organismos que han considerado a Israel Potencia Ocupante en la Franja de Gaza cabe destacar el CICR, ya que en un pequeño informe de noviembre de 2005 consideró a la Franja de Gaza como territorio ocupado ${ }^{114}$. Sin embargo, esta ha sido también la posición defendida más tarde por el Presidente del CICR, Peter Maurer, en $2012^{115}$. Y es que el Presidente del CICR señaló en una Conferencia relacionada con los territorios ocupados que los problemas humanitarios acechaban a la región del Próximo Oriente, de manera que después de mencionar los problemas humanitarios a causa del conflicto con Siria y en otras zonas con el resurgir de la Primavera Árabe, así como en Yemen, se centra en el tema israelo-palestino considerándolo como el "problema humanitario sin duda más antiguo y tenaz de toda la región, en la que la situación de alienación durable de la población palestina que vive bajo un régimen de ocupación en Cisjordania y en la Franja de Gaza, o desplazada en los campos de refugiados de toda la región..."116. Y en relación con Gaza, vuelve a cargar al señalar que "Israel exerce une 'autorité de fait' sur la Cisjordania et sur la bande de Gaza depuis près d'un demi siècle. Sa prèsence sur ces territoires constitue de ce fait, l'une des plus longues occupations militaries continues, de l'histoire moderne. Si la forme et le degrè de cette occupation militaire ont variè au fil de temps, Israël a exercé sans discontinuer une autorité effective sur les territorires qu'il a occupé à l'issue de la guerre de Six Jours en 1967 et sur la population palestinienne qui y réside" $" 117$.

Estas afirmaciones del Presidente del CICR suscitará una dura reacción del israelí Alan Baker ${ }^{118}$, quien le reprocha que está violando los principios fundamentales de imparcialidad y neutralidad tal y como están recogidos en los Estatutos del Movimiento Internacional de la Cruz Roja $^{119}$. Y respecto a Gaza, critica acerbamente las afirmaciones que ha hecho Peter Maurer, según las cuales Israel continuaría siendo "Potencia Ocupante en la Franja de Gaza al ejercer una autoridad efectiva, recurriendo a "medidas coercitivas" que obstaculizan "los esfuerzos destinados a construir instituciones democráticas dignas de este nombre bajo la autoridad administrativa palestina", y que por lo tanto Israel sería responsable de la situación económica y social que asola este territorio. Cuando Israel se ha retirado unilateralmente hace ya ocho años esas afirmaciones parecen indicar un conocimiento aproximativo sobre su situación real sobre el terreno ${ }^{120}$. Es más, este ex-Embajador en Canadá y ex-Consejero jurídico en el Ministerio de Asuntos Exteriores de Israel, no perdona a Peter Maurer que ignore que la zona ha sido ocupada por Hamás, que ha expulsado física y brutalmente a la Autoridad Palestina, y que ha

\footnotetext{
113 Stephanopoulos, Nicholas.: "Israel's Law Obligations to Gaza After the Pullout”, Yale Journal of International Law (2006), p. 524.

${ }^{114}$ Dignity Denied in the Occupied Palestinian Territories, noviembre 2005, $10 \mathrm{p}$.

${ }^{115}$ Maurer, Peter : "Obstacles au droit international humanitaire : la politique israélienne d'occupation”, Revue internationale de la Croix-Rouge (2012), pp. 323-331.

116 Ibid, p. 324.

117 Ibid, p. 325.

${ }^{118}$ Baker, Alan: "Le droit international humanitaire, le CICR et le statut d'Israël dans les territoires", Revue internationale de la Croix-Rouge (2012), pp. 333-343.

${ }^{119}$ Ibid, pp. 335-337.

${ }^{120}$ Ibid, p. 336.
} 
establecido su propia autoridad militar y su administración islamista integrista totalmente opuesta a cualquier forma democrática de Gobierno. Estos hechos han sido acompañados de una política represiva, y por violaciones continuas y sistemáticas tanto en relación con la propia población local como por las ciudades y pueblos próximos a la Franja de Gaza, así como por numerosos ataques terroristas tanto en Israel como en el territorio egipcio del Sinaí ${ }^{121}$.

Pero las ideas de Peter Maurer tampoco parecen ser bien recibidas por Shawan Jaburin, quien después de trazar sucintamente las ideas expresadas por el Presidente del CICR, le reprocha también su falta de confidencialidad y de neutralidad a la hora de abordar el conflicto israelo-palestino $^{122}$.

Si vamos ahora a las Naciones Unidas, el Consejo de Derechos Humanos también se ha ocupado de esta cuestión, así como el propio Secretario General. Los posicionamientos de este último han sido al principio favorables a la tesis según la cual Israel había guardado un nivel de control sustancial sobre la Franja de Gaza, aunque sus tropas no tuvieran presencia física en el territorio $^{123}$. Sin embargo, esta tesis se ha ido quedando un poco ambigua en posteriores Informes emitidos al respecto, así como en el propio Consejo de Derechos Humanos. Esta nueva visión del tema se debe a las guerras que Israel ha mantenido con Hamás tras hacerse con el poder en 2007 en la Franja de Gaza, que han puesto de manifiesto la realidad existente en la zona. En el Informe de John Dugard ${ }^{124}$, se sigue manteniendo la misma opinión que la del Secretario General, aunque el que suscitaría más polémica sería el denominado "Informe Goldstone" a pesar de que se reconoce que "Since July 2007 Hamás has been de facto government authority in Gaza. As recognized by the israelí Government, the Hamas-led authorities in Gaza have been responsible for the civilian administration of Gaza"125.

El Informe Goldstone, suscitaría tal polémica, que, a pesar de que abordaba en realidad la Operación "Plomo Fundido" de Israel en la Franja de Gaza, y las violaciones de los Derechos Humanos que se habían cometido, fue acusado de arbitrario y parcial. A pesar de que Goldstone era de origen judío sudafricano, este Informe tuvo una respuesta del también judío Alan Deshowitz, quien le pidió que explicara las evidentes parcialidades que contenía el Informe y la metodología utilizada, ya que, si no lo hacía, asumía implícitamente que el Informe no era digno de ser tomado en consideración por la gente de buena voluntad ${ }^{126}$. Como es sabido,

\footnotetext{
${ }^{121}$ Ibid, p. 338. Y añade : "ne pas tenir compte des actes de terreur qui émanent de la bande de Gaza et qui visent délibérément la population civile d'Israël et négliger la menace constante que pose pour la sécurité d'Israël l'accumulation constante d'armes et de missiles offensif revient à nos yeux à travestir la réalité".

${ }^{122}$ A este respecto, este asesor de "Human Rights Watch" para el Medio Oriente afirma lo siguiente : "J'ai toujours été préocupé par la politique de confidentialité du CICR, surtout lorsque de graves violations du DIH susceptibles de constituer des crimes de guerre et des crimes contre l'humanité sont commises et lorsque les principes essentiels du DIH sont manipulés de façon à justifier l'occupation militaire d'un territoire. Si la philosophie qui sous-temá la diplomatic discrète du CICR relève de la neutralité de celui-ci, le fait qu'il ne prenne pas position publiquement risque d'être considéré par les auteurs de crimes comme un signe d'occuptation...". Véase : Shawan Jabarin en su estudio "Le territoire palestinien occupé et le droit international humanitaire. Réponse à Peter Maurer", Revue internationale de la Croix-Rouge (2013), p. 162. Ver también p. 174.

123 Situation des droits de l'homme dans les territorires palestiniens occupés depuis 1967, UN, Doc. /A/61/470, de 27 de septiembre 2006, párrafo 6.

${ }^{124}$ Dugard, John : Rapport sur la situation des droits de l'homme dans les territoires palestiniens occupés, Rapporteur special, E/CN.4/2006/29 de 17 janvier 2006, párrafos 6 y ss.

${ }^{125}$ United Nations, General Assemby Human Rights Council: Human Rights in Palestine and Other Occupied Arab Territories Resort of the United Nations Fact-Finding Mission on the Gaza Conflict, Doc. A/HRC/12/48, 25 septiembre 2009, p. 97, párrafo 383. Ver también las pp. 59-60 en relación con la estructura administrativa en Gaza antes de 2007.

${ }^{126}$ Deshowitz, Alan (2009): The Case Against Goldstone Report: A Study in Evidentiary Bias, Harvard Library, 2009. En este Informe, sumamente detallado, Alan Deshowitz le pide lo siguiente: "So now it is up to Richard Goldstone to explain the evidentiary bias that it is obviously reflected in the report. The burden is on him to justify the very different methodologies used in the report to arrive at its conclusions regarding the intentions of Israel
} 
Richard Goldstone se arrepintió después, al darse cuenta de que no tenía ni le habían dado toda la información necesaria para juzgar la Operación "Plomo Fundido" en Gaza entre diciembre y enero de 2008 y $2009^{127}$, ya que, si lo hubiera tenido, hubiera llegado a otras conclusiones. Pero al margen de estas cuestiones, lo más importante para el tema que nos ocupa es que ya se parte de la premisa de que Hamás tiene un Gobierno de facto en la Franja de Gaza, y que ese Gobierno ni depende de Ramalla ni de Jerusalén.

Otro Informe más reciente del Consejo de Derechos Humanos, vuelve a insistir en el hecho de que Hamás ejerce de facto las funciones de Gobierno en Gaza al señalar textualmente que: "The events of summer 2014 were preceded by an agreement reached on 23 April 2014 between the Palestinian Liberation Organization and Hamas, which sought to end Palestinian divisions. On 2 June 2014, President Abbas declared the formation of a Government of national consensus. The Government had yet to assume its full responsibility in Gaza when active hostilities broke out in the Strip in July 2014, thereby leaving Hamas exercising governmentlike functions, as had been the case since June 2007"128. En este Informe también se reconoce, pues, que las funciones gubernamentales las lleva Hamás. ¿Se podrá atribuir a Israel los cohetes y misiles que Hamás lanza desde hace tiempo contra la población civil del propio Israel?

Otros autores, sin embargo, defienden rotunda y expresamente que la retirada de Israel de la Franja de Gaza es completa, y que de facto se dan todos los elementos para que Israel no sea considerada tras la retirada como Potencia Ocupante. Tal es el caso de Yuval Shany, que nos recuerda lo que ya dijo el Tribunal Militar estadounidense en el ya citado Caso Hostages, en el que expone muy claramente cuando se está ante una Ocupación o no ${ }^{129}$. Ya la pregunta que se hace sobre si Gaza está ocupada o no ${ }^{130}$ da unos elementos convincentes que demuestran en su opinión que la Franja de Gaza no está ocupada desde la retirada israelí el 12 de septiembre de $2005^{131}$.

Otros autores se han pronunciado sobre esta cuestión señalando que los textos convencionales en esta materia dejan claro que la capacidad de una Potencia Ocupante de imponer su autoridad no puede disociarse de su presencia física en el territorio sometido a control, y la mayoría de las reglas relativas a la Ocupación no pueden concebirse sin poner en funcionamiento en el territorio ocupado un sistema de administración. Y es que, como apuntan

and the intentions of Hamas. Failure to assume that burden will constitute an implicit admission that the conclusions reached in the Goldstone Report are not worthy of consideration by people of good will. I await his response", p. 50. http://nrs.harward.edu/urn-3:HUL.InstRepos:3593975

${ }^{127}$ Bowcott Owen:"Richard Goldstone: the judge who 'regrets' his Gaza report", The Guardian, 5 April 2011, en https://www.theguardian.com/world/2011/apr/05/richard.goldstone-judge-gaza-report

${ }^{128}$ United Nations. Human Rights Council, Report of the Independent Commission of Inquiry established pursuant to Human Rights Council Resolucion S-21/1, Doc. A/HRC/29/52, 24 June 2015, párrafo 17.

${ }^{129}$ Shany, Yural.: "Faraway, so Close: The Legal Status of Gaza...", op. cit., p. 374, en donde recoge el texto siguiente del Tribunal: "The term invasion implies a military operation while an occupation indicates the exercise of governmental authority to the exclusion of the established government. This presupposes the destruction of organised resistance and the establishment of an administration to preserve law and order. To the extent that the occupant's control is maintained and that of the civil government eliminates, the area will be said to be occupied". ${ }^{130}$ Ibid, p. 379.

${ }^{131}$ A este respecto, en su Conclusión a este estudio, es sumamente claro y al mismo tiempo categórico, al señalar que "The Israeli Disengagement from Gaza has led, in my view, to the transfer of effective control over the entire Gaza Strip from Israel to the PA. While it is hard to ascertain at which precise point in time the control exercised by the PA became more effective than that exercised by Israel, actually or potentially. I would argue that this moment has arrived, and that the preponderance of authority over Gaza is now invested with the PA...". Ibid, p. 383. Remárquese que este estudio se ha publicado antes de la toma del poder de Hamás en Gaza en 2007. Este autor volvería a la carga defendiendo esta tesis en los trabajos siguientes, ya tras la toma del poder de Hamás en la Banda de Gaza. A este respecto véase Shany, Yural.: "The Law Applicable to Non-occupied Gaza: A Comment on Bassiauni v. the Prime Minister of Israel", Israel Law Review (2009), pp. 101-114; del mismo autor "Binary Law Meets Complex Reality: The Occupation of Gaza Debate”, Israel Law Review (2008), pp. 68-86. 
Robert Kolb y Sylvain Vité "Il es en effet imposible d'assurer l'ordre et la vie publics d'un territoire depuis l'extérieur. Il serdit ainsi paradoxal d'exiger qu'un Etat satisfasse à ses obligations internationales sans qu'il soit en mesure de la faire en raison de son absence des territoires concernés. Pareille interprétation irait à l'encontre des fondements mêmes du droit de l'occupation""132.

Esta misma línea de pensamiento es la que sigue Hanne Cuyckens a pesar de las funciones que ha retenido Israel tras la Desconexión. Señala a este respecto, que: “...The fact that Israel is not de sole authority exercising some form of authority over the Gaza Strip is, in my opinion problematic in this regard. Indeed, since June 2007, Hamas carries out most of the governmental administration functions as wild as being responsible for public services such as education, policing sanitation and hospitals"133. Es más, señala que no ve cómo Israel va a poder ejercer un cierto control jerárquico sobre Hamás si no es recurriendo a combates importantes para poder reocupar la zona ocupada ahora por las fuerzas de Hamás, y si este es el caso no se puede considerar que el territorio pueda ser ocupado por un tiempo suficientemente largo. Pero es que, además, esto requeriría unas operaciones militares de gran envergadura, y por consiguiente no sería posible llevarlas a cabo "en un tiempo razonable" ${ }^{134}$. Desde esta perspectiva, no es extraño que la autora aluda a las guerras de envergadura que Israel ya ha mantenido con Hamás desde que tomó las riendas de Gaza en 2007. Para apoyar estos argumentos, la autora recurre a la Corte Suprema de Israel que, en la cuestión que nos ocupa, ha dejado claro en el caso Al-Bassiouni ${ }^{135}$ que Israel no ejerce desde septiembre de 2005 un "control efectivo sobre lo que sucede en Gaza"136.

En efecto, en este caso la Corte Suprema de Israel hace una diferencia importante entre las obligaciones que incumben a Israel en virtud del Derecho internacional humanitario de aquellas que le incumbirían en tanto que Potencia Ocupante ${ }^{137}$. Así pues, se trataba de examinar si las restricciones que había adoptado el Gobierno de Israel en la oferta de petróleo y electricidad a la Franja de Gaza a finales del año de 2007 podían considerarse como apropiadas o no. El Gobierno israelí defendía que el petróleo y la electricidad que se daba a la Franja de Gaza eran utilizados para apoyar a las operaciones terroristas que se estaban llevando a cabo en Israel, incluyendo el lanzamiento de cohetes hacia Israel. Desde este prisma, una reducción controlada de estos productos podría dañar la infraestructura terrorista y la operatividad de Hamás sin afectar demasiado desde el punto de vista humanitario el hecho de que se redujera la oferta de estos productos. La Corte, que examinó minuciosamente los hechos y los efectos que podían tener a nivel humanitario, denegó la petición presentada por Al-Bassiouni, señalando que en virtud de las reglas del Derecho internacional humanitario que la Corte tenía que aplicar lo permitían. A este respecto la Corte declaró:

\footnotetext{
${ }^{132}$ De estos autores, Le droit de l'occupatión militaire..., op. cit., p. 180. Estos autores hacen referencia a la jurisprudencia internacional de varios casos en la materia. Ver también, Vité, Salvain : "Typologie des conflits armés en Droit international humanitaire : concepts juridiques et politiques”, 21 p., especialmente, pp. 12-13, en relación con la Franja de Gaza. Este estudio se ha publicado en inglés con el título "Typologie of Armed Conflicts in International Humanitarian Law: Legal Concepts and Actual Situations", Int. Rev. Red. Cross, 2009, pp. 69-74, especialmente, pp. 83-85 en relación con Israel.

${ }^{133}$ Cuyckens, Hanne.: "Is Israel Still an Occupying Power in Gaza?", op. cit., p. 285.

${ }^{134}$ Ibid.

${ }^{135}$ Al-Bassiouni Ahmed and Others v. Prime Minister and Ministre of Defence, Case 9132/07, 27 January 2008, párrafo 12. Sobre este asunto. Shany, Yuval.: "The Law Applicable to Non-occupied Gaza: a Comment on Bassiouni v. The Prime Minister of Israel”, op. cit., 2009, pp. 101-116.

${ }^{136}$ Cuyckens, Hanne.: "Israel Still an Occupying Power in Gaza?", op. cit., p. 286.

${ }^{137}$ Para un estudio sobre la jurisprudencia de la Corte Suprema israelí en materia de Derecho Internacional Humanitario, véase Raguan, Galit.: “Adjudicating Armed Conflict in Domestic Courts: The Experience of Israel's Supreme Court”, Yearbook of International Humanitarian Law 2010, pp. 61-95. La Corte se tendría que ocupar también de otras demandas presentadas a raíz de la Operación Plomo Fundido.
} 
"In the prevailing circumstances, the main obligations of the State of Israel reting to the residents of Gaza Strip derive from the state of armed conflict that exists between it and the Hamas organizations that control the Gaza Strip; these obligations also derive from the degree of control exercised by the State of Israel over the border crossing between it and the Gaza Strip, as well as from the relationship that was created between Israel and the territory of the Gaza Strip after the years of Israeli military rule in the territory, as a result of which the Gaza Strip is currently almost completely dependent upon the supply of electricity from Israel" 138.

Sin embargo, en relación con las obligaciones que le podrían incumbir a Israel como eventual Potencia Ocupante, dejó claro que no lo era, y lo hizo en los términos siguientes:

“... since September 2005 Israel no longer had effective control over what happens in the Gaza Strip. Military rule that applied in the past in this territory came to an end by a decision of the government, and Israeli soldiers are no longer stationed in the territory on a permanent basis, nor are they in charge of what happen there. In these circumstances, the State of Israel does not have a general duty to ensure the welfare of the residents of the Gaza Strip or to maintain public order in the Gaza Strip according to the laws of belligerent occupation in international law. Nor does Israel have any effective capability, in its present position, of enforcing order and managing civilian life in the Gaza Strip"139.

Así las cosas, todo apunta a que este debate en torno a Gaza está sirviendo para colmar lagunas que se vislumbran en el ámbito del Derecho internacional humanitario sobre todo en casos de ocupación longa manu. Y es que basta con contemplar el caso gazaoui para darse cuenta de la complejidad que encierra a nivel jurídico y político el régimen de Ocupación, que puede ir evolucionando hacia una solución del conflicto, que era lo que el Gobierno israelí de Ariel Sharon quería hacer con Gaza, o hacia una situación de conflicto quasi permanente, que es lo que al final ha ocurrido, sobre todo tras la llegada al poder de Hamás. Sería un sinsentido no tomar en consideración esta realidad, cuando los hechos nos demuestran que las guerras de una especial intensidad militar que ha habido desde entonces demuestran a todas luces que Israel no ejerce el control efectivo sobre ese territorio, ni está en condiciones de ejercerlo. Dicho esto, también conviene recalcar que el hecho de que Israel no sea ya Potencia Ocupante no le exime de otras obligaciones humanitarias debido al hecho de las competencias que se ha reservado, como el control de las fronteras terrestres, marítimas y aéreas, y a esto precisamente es a lo que se refiere la Corte Suprema de Israel en este caso Al-Bassiauni. No obstante, aquí ya nos situamos fuera del régimen de Ocupación y entramos en el ámbito de obligaciones humanitarias o del Derecho internacional de los Derechos Humanos.

\section{Algunas reflexiones en torno al estatuto de Gaza}

Como pensamos haber demostrado en las páginas precedentes, el Estatuto actual de Gaza es complejo, pero lo único que parece estar claro es que Israel no se puede considerar que continúe siendo Potencia Ocupante desde que unilateralmente se retiró de la Franja en agosto y septiembre de 2005. Las polémicas doctrinales e institucionales que se han suscitado al respecto son comprensibles, pero eso no impide sostener que en el estado actual del Derecho que rige la Ocupación de un territorio, Israel no es Potencia Ocupante. Los que defienden la tesis de que Israel lo sigue siendo, parece que para ellos nada ha cambiado tras la Desconexión, lo que desde nuestro punto de vista eso no es nada más que una ficción. Es más, incluso algún autor, a pesar

\footnotetext{
${ }^{138}$ Al-Bassiouni and Others v. Prime Minister..., op, cit., párrafo 12.

${ }^{139}$ Ibid.
} 
de que considera, al parecer no muy convencido, que Israel continúa siendo Potencia Ocupante, nota algo nuevo bajo el sol, al indicar lo siguiente:

"Mais bien sûr, il s'est passé qulque chosde depuis l'évacuation militaire; Israël n'exerce plus les fonctions d'autorité qu'il exerçait lorsque ses troupes occupaient la Bande, et par suite ne peut plus être tenu par les mêmes obligations. Demeure cependand une responsabilité résiduelle aux contours mal défénis, mais qui pourrait être mesurée à l'importance des pouvoirs conservés" ${ }^{140}$.

En efecto, mucho ha cambiado sobre el terreno con la Desconexión tanto a nivel fáctico como jurídico y político. A nivel fáctico lo notan los gazaouis como los israelíes. Los primeros por su dependencia extrema del exterior, y ser un territorio desconectado de Cisjordania, algo que, aunque se sepa, lo olvidan muchos analistas. Pero su dependencia para hacer frente a sus necesidades depende también de otro elemento fáctico, su poca extensión territorial, $365 \mathrm{~km}^{2}$, y su numerosa población, en torno a dos millones. Al no tener conexión territorial con Cisjordania, sus límites son de $51 \mathrm{~km}$. con Israel, y 11 con Egipto, y al oeste el Mar Mediterráneo, pero cuyas aguas territoriales son controladas por Israel. Todo esto hace que la Franja de Gaza se vea supeditada a satisfacer sus necesidades vitales en buena medida del exterior $^{141}$. Jurídicamente hablando, ya hemos hecho alusión a la complejidad existente, y desde el punto de vista político, la Desconexión ha supuesto problemas para ambos pueblos, el de Gaza y el de Israel, tal y como nos lo pone de relieve la actualidad internacional. Las guerras de una cierta envergadura que han tenido lugar ${ }^{142}$ tras la Desconexión, y la posterior toma del poder por parte de Hamás en Gaza, están ahí para demostrarlo. Pero la Desconexión también ha planteado serios problemas para la población del Sur de Israel, hostigada a menudo por los cohetes y misiles que llegan desde Gaza, así como por los famosos túneles que causaron bastantes bajas entre los soldados israelíes en la Operación "Margen Protector". Y es que, como ya se ha apuntado por mandos militares israelíes, la Desconexión ha traído consigo una cierta incertidumbre a la hora de hacer frente a las amenazas que procedían de ese territorio, al perder su control efectivo y, por tanto, poder adoptar medidas preventivas para su seguridad ${ }^{143}$.

\footnotetext{
${ }^{140}$ Bockel, Alain.: "Le retrait israélien de Gaza...", op. cit., p. 23.

${ }^{141}$ A estos elementos peculiares de la Franja de Gaza alude también Yaval Shany, en su trabajo "Faraway: The Legal Status of Gaza...", op. cit., p. 172.

${ }^{142}$ La Operación Plomo Fundido, diciembre 2008, enero de 2009; la Operación Pilar Defensivo, de finales de 2012; la Operación Margen Protector, quizás la más dura; del verano de 2014; y la guerra de finales de 2018, que ha sido en gran medida evitada gracias a un pronto cese del fuego negociado por Egipto y algunos países árabes. ${ }^{143}$ A este respecto, son muy pertinentes las palabras del General israelí Gevshon Hacohen, quien en relación con este tema señala lo siguiente: "The Hamas leadership certainly knows the strength of the IDF relative to the strength of its own forces. But it bases its decisions not on the calculation but on its assessment of the constraints that prevent the Israeli government from making the decision to go to war...". Y este General parece preguntarse a quien favorece la Desconexión, y la respuesta que da dista mucho de que favorezca a Israel. "It is time to challenge the assumption that spatial separation benefits Israel. Supporters of with- drawal from the West Bank, including most senior members of the former security establishment, base their thinking on the belief that the attendant risks of withdrawal and territorial separation can be mitigate by the fact that the IDF's continuous superiority can remove, within days, any security threat emanating from the territories vacated by Israel. But since the beginning of the Oslo process, something significant has changed in relations between Israel and the Palestinians and in recent decades there has been a global change in the phenomen of war... Their assessment of the IDF's relative strength is thus consistenly over estimated. Looking at the Gaza Strip prior to the IDF withdrawal we see that although there was a fence that delineate the Strip, most of the IDF forces operated within the area base on the deployment of the Israeli villages in the southj of the Strip. This created flexible operational potential for the IDF forces, wich could reach enemy area, from a variety of directions... The redeployment of forces and their reliance on a security fence in linear arrays made the fence a focal point for friction, and created the conditions for Hamas to organice its forces according to battalions, brigades, firing lines and command and control systems. In this respect, territorial separation helped Israel's enemies and harmed the IDF's freedom of action. Hacohen, Gershon.: "Israeli Security Concept: Wandering Through a Maze", The Beguin-Sadat Center for Strategig Studies,
} 
Así las cosas, el análisis de la actual situación en la Franja de Gaza requiere esa división neta entre las reglas del régimen de Ocupación, de aquellas otras que incluso fuera del hecho de que Israel ya no sea Potencia Ocupante, estará obligado a cumplir bien porque le incumban por haber retenido un ámbito preciso de competencias, o bien porque esté obligado por el Derecho internacional humanitario ${ }^{144}$ y por el Derecho internacional de los Derechos Humanos ${ }^{145}$, e incluso por ciertas disposiciones de la IV Convención de Ginebra relativas sobre todo a la prestación de asistencia humanitaria. Y es que, como ya señaló en 2005 Yuval Shany “... although it is undeniable that Israel retains some powerful points of leverage over the lives of Palestinians in Gaza, it would seem difficult to maintain that such leverage enables Israel to effectively govern Gaza, i.e., to effectively control day-to-day life in the area" ${ }^{146}$. Es este planteamiento el que permitiría ver una cierta claridad en el oscuro túnel de Gaza, rechazando así tesis expansivas como aquellas que pretenden unificar la situación de Gaza con la de Cisjordania, señalando que como Cisjordania está ocupada también tiene que estar la Franja de Gaza, tesis que ha mantenido Yoran Dinstein ${ }^{147}$. Es más, esta opinión no es muy conforme con el Derecho vigente, pues tanto el artículo 2 del Cuarto Convenio de Ginebra como el artículo 42 del Reglamento de La Haya dicen expresamente que puede haber una ocupación de parte del territorio de una Alta Parte Contratante, al decir expresamente que "la ocupación no se extiende sino a los territorios donde esa autoridad esté establecida y en condiciones de ejercerse".

Desde esta perspectiva, y dada la complejidad del caso de la Franja de Gaza, algunos posicionamientos han lanzado la idea de recurrir a un enfoque funcional, con el fin de delimitar las competencias entre la que consideran todavía como Potencia Ocupante, Israel, y la Autoridad del territorio ocupado, que era hasta el 2007 la Autoridad Palestina y desde entonces Hamás. Esta es la tesis que ha defendido el Ghisa Center, que partiendo del principio según el cual "... The Law of occupation continues to apply to the Gaza Strip (in addition to the West Bank) in the areas in which Israel maintains control over the lives of Palestinian residents, while in the areas in which it has transferred or relinquished its powers and allows others to exercise them-its responsibility vis-à-vis the civilian population is diminished or extinguished" ${ }^{148}$. Y es que se "compara la complejidad que encierra el caso de Gaza 'to a seam zone between occupation and sovereignity...' o si se quiere como una especial de 'indeterminacy' of occupation" 149 .

Un año más tarde el Consejero Jurídico del CICR, Tristan Ferrero vuelve a insistir en esta misma idea, aunque de una manera más sutil, al decir lo siguiente: "However in some specific and exceptional cases-in particular when foreign forces withdraw from occupied territory (or parts thereof) while retaining key elements of authority or other governmental functions therein which are typical of those usually taken on by an Occupping Power-it is proposed here that occupation law might continue to apply within the territorial and functional

15 Novembre 2018. Como se puede ver, este Geneval reconoce que Israel ya no controla la Franja, y que esto les plantea problemas, pues Hamás es libre de organizarse como quiera.

${ }^{144}$ No hay que olvidar que las operaciones que llevan a cabo las fuerzas armadas israelíes alrededor de Gaza se rigen por este Derecho.

${ }^{145}$ A este respecto, conviene remarcar que la Corte Suprema de Israel siempre ha sido consciente de esto en los territorios ocupados en general, pero también la doctrina israelí. Entre esta última, por ejemplo, Ben-Naftali, Oma y Shany, Yuval.: "Living in Denial: The Application of Human Rights in the Occupied Territories", Israel Law Review (2003-2004), pp. 17-118, especialmente pp. 64-65. Para una posición muy crítica en relación con el trato de Israel a los ciudadanos de Gaza, Luft, Michal.: "Living in a Legal Vacuum: the Case of Israel's Legal Possition and Policy Towards Gaza Residents", Israel Law Review (2018), pp. 193-234..

${ }^{146}$ Favaways, C.: "The Legal Status of Gaza...", op. cit., p. 382.

147 The International Law of Belligerent Occupation..., op. cit., párrafo 666.

${ }^{148}$ Ghisa, Scale of control: Israel's Continued Responsibility in the Gaza Strip, op. cit., p. 26.

${ }^{149}$ Ibid, p. 30. 
limits of those competences" 150 . Y se justifica este enfoque functional porque permite, dice, una delimitación más precisa del marco legal aplicable a situaciones en las que es difícil determinar con certeza si la Ocupación ha terminado ya o no ${ }^{151}$. Es decir, no tiene claro si Israel sigue siendo Potencia Ocupante todavía o no, de ahí que utilice este resquicio ${ }^{152}$.

Este mismo enfoque ha sido adoptado en 2015 por el CICR en la trigésimo segunda Conferencia de la Cruz Roja que tuvo lugar el 8-10 de diciembre de 2015 $5^{153}$. Al tratarse el tema del principio y del fin de la ocupación, el CICR defiende que el denominado "effective-control test" no siempre permite llegar a la conclusión de que una Ocupación ha terminado, al menos desde un punto de vista jurídico: "The end of an occupation may also be difficult to assess from a legal perspective. The legal classification of a given situation and the determination of when an occupation may be said to have ended can be complicated by several factors, such as progressive phase-out, portral witctdrawal, retention of certain competences over previously occupied areas, or the maintenance of military presence on questionnable consent"154.

De estos elementos, pensamos que en el caso que nos ocupa, el CICR está pensando aquí en las competencias que Israel se ha reservado al controlar las fronteras terrestres, marítimas y aéreas, así como al imponer que este territorio sea desmilitarizado. La pregunta que uno puede y debe hacerse es saber si esto es suficiente para poder llegar a la conclusión de que Israel controla de facto el territorio, y si está en condiciones de ejercer su autoridad en él, algo que a todas luces no es el caso, como ya hemos puesto de manifiesto. Pretender como hace el $\mathrm{CICR}^{155}$ que la falta de tener físicamente fuerzas sobre el territorio pueda compensarse con la autoridad que pueda ejercer Israel sobre las fronteras para el "effective-control test", es ampliar artificialmente el régimen de Ocupación internacional vigente, no previsto ni en el Reglamento de La Haya ni en el Cuarto Convenio de Ginebra. Y tampoco compartimos la invocación que hace el CICR al desarrollo tecnológico y militar para pretender que no es necesario una presencia física en el territorio, porque los hechos han demostrado lo contrario, y mucho menos recurrir a la contigüidad geográfica entre los contendientes ${ }^{156}$ ya que en este caso otros territorios también podrían considerarse como ocupados al hacer una interpretación tan extensiva. Así pues, este enfoque funcional, que parece prima facie atractivo, plantea a nuestro entender más problemas que soluciones, y requiere un análisis más profundo de los problemas que plantea para la Franja de Gaza, un territorio exiguo, densamente poblado y con decenas de miles de funcionarios y personal de seguridad, con diversas organizaciones y grupos armados

\footnotetext{
${ }^{150}$ Ferraro, Tristan: "Determining the Beginning end of an Occupation under International Humanitarian Law", op. cit., p. 157.

${ }^{151}$ Ibid.

${ }^{152}$ Esta actitud no está presente en el Informe precitado del Ghisa Center, más radical a la hora de considerar a Israel como Potencia Ocupante.

${ }^{153}$ A este respecto véase: International Humanitarian Law and the Challenges of Contemporary Armed Conflicts, Document prepared by the International Committee of the Red Cross for the $32^{\text {nd }}$ International Conference of the Red Cross and Red Crescent, Geneva, Switzerland, 8-10, December 2015, en International Review of the Red Cross (2015), pp. 1427-1502.

${ }^{154}$ Ibid, p. 1438.

155 "The ICRC considers however, that in some specific and rather exceptional cases -in particular when foreign forces withdraw from occupied territory (or parts thereof) but retain key elements of authority or other important governmental functions usually performed by an occupying power- the law of occupation may continue to apply within the territorial and functional limits of such competences. Indeed, despite of the lack of physical presence of foreign forces in the territory concerned, the retained authority may amount to effective control for the purposes of the law of occupation and entail the continued application of the relevant provision of this body of norms", Ibid, pp. 1438-1439.

${ }^{156}$ Ibid, p. 1439.
} 
allí presentes ${ }^{157}$, Con estas circunstancias, este enfoque funcional serviría para hacer de Israel el causante de todos los problemas que tiene Gaza, algo que incluso se intenta hacer ahora ${ }^{158}$.

Dicho esto, no queremos pretender aquí que el régimen actual de ocupación sea perfecto, y ya hemos comentado algo al respecto, ni que no presente en ciertos casos una serie de aristas, e incluso lagunas en algunos casos, como puede ser el de Gaza, pero esto no tiene por qué implicar tergiversar el derecho y recurrir a argumentos que no son de lega data, y por lo tanto, aunque puedan ser deseables en algunos o muchos de sus aspectos, solo se podrán invocar como de lega ferenda ${ }^{159}$. Es más, modificar el sistema internacional de ocupación vigente para aplicarlo a Gaza según unos determinados parámetros previstos por una Parte, no solo no es jurídicamente correcto, sino que además es, desde el punto de vista político un atropello, pues generaría una grave desconfianza en las normas internacionales y contaminaría el sistema de una cierta parcialidad o, incluso, de arbitrariedad.

En un caso como es el de la Franja de Gaza, controvertido jurídicamente, y que arrastra los elementos políticos que todos conocemos, es muy fácil pretender que todos los males que están presentes en la zona se deben a que Israel, como presunta Potencia Ocupante, no cumple sus obligaciones, sin preguntarse en absoluto por qué esa situación subsiste tras casi quince años de la Desconexión y retirada de las fuerzas israelíes del territorio. Por eso el caso ya citado y comentado de Al-Bassiouni, de la Corte Suprema de Justicia de Israel, es sumamente interesante, pues aborda esta cuestión desde esa triple perspectiva ${ }^{160}$, y tanto el hecho de que las fronteras estén controladas por Israel, como la importancia que puede tener el hecho de haber sido Potencia Ocupante durante un largo tiempo sobre la Franja de Gaza, puede generar una serie de obligaciones para Israel. Pero la Corte no entra en el fondo de estas dos cuestiones, sobre todo en el tema de las fronteras, mientras que en relación con el largo período de ocupación considera que esa situación ha traído consigo que dependa "almost completely upon the supply of electricity from Israel"161.

Desde esta perspectiva, tras invocar el Estado de Israel el artículo 23 del Cuarto Convenio de Ginebra, y considerar que el artículo 70 del Protocolo Adicional I, del que Israel no es parte, pero que es considerado como norma consuetudinaria, la Corte acepta las tesis del Gobierno israelí al considerar que las restricciones de diésel y de electricidad a Gaza "son capaces de satisfacer las necesidades humanitarias esenciales que actualmente necesita ese territorio". Lo que la Corte deja muy claro es que Israel y Hamás tienen un conflicto armado

\footnotetext{
${ }^{157}$ Como se sabe, en todas las operaciones militares desencadenadas en Gaza por Israel tras la Desconexión, las fuerzas israelíes se han encontrado con este problema, al haber una alta población civil mezclada con objetivos militares, imposibilitando así llevar a cabo las operaciones militares tal y como se desearía. Es más, las fuerzas terrestres solo han entrado en unos pocos kilómetros dentro de la Franja. Sobre los problemas que se plantean a nivel del Derecho internacional humanitario en esta clase de situaciones, Maurer, Peter: "War in Cities: What is at Stake?", Int. Rev. of the Red Cross (2016), pp. 639-646.

${ }^{158}$ Sobre estas cuestiones, Shany, Yuval.: "Binary Law Meets Complex Reality: The Occupation of Gaza Debate", Israel Law Review, 2008, pp. 68-86.

${ }^{159}$ Desde esta perspectiva podemos compartir lo que ha señalado a este respecto Valentina Azareva, al afirmar que: "Whilst the law of occupation does not explicitly provide for a 'transitional' legal framework that regulates the process of termination, the simplicity of the above mentioned criteria for termination falls short of answering more demanding practical questions, such as: What duties does an occupying power have during the transition to restoration of lawful sovereignty? Haw can occupation law be applied to situations in which an occupying power has partially retreated but continues to exercise governmental functions?". Azarova, Valentina: Disingenuous 'Disengagement': "Israel's Occupation of the Gaza Strip and the Protective Function of the Law of Belligerent Occupation". Symposium on the Functional Approach to the Law of Occupation. Opinio iuris (April 2012), en http://opiniojuris.org/2012/04/23/symposium-on-the-functional-approach-to-the-law-ofoccupation

160 Véase supra.

${ }^{161}$ Al-Bassiouni and Others v. Prime Minister..., op. cit., párrafo 12 in fine.
} 
que es internacional, teniéndose que aplicar sin fisuras el Derecho internacional humanitario ${ }^{162}$. Pero el veredicto de la Corte Suprema israelí no aclara en realidad mucho el Derecho internacional aplicable en el ámbito de esas obligaciones que podrían considerarse posocupacionales, aunque recurre en su trasfondo a obligaciones humanitarias que podrían caer tanto en el marco del Derecho internacional humanitario como en el de los Derechos Humanos ${ }^{163}$. El hecho de que la Corte Suprema de Israel señale que Israel se encuentra en un estado de conflicto armado con Hamás en la Franja de Gaza es significativo, a pesar de que no haga alusión directa al Derecho internacional de los Derechos Humanos. Y es que Israel es uno de los pocos Estados que considera, como lo hacen también los Estados Unidos, que en caso de conflicto armado, el Derecho internacional humanitario es el único aplicable para las Partes en conflicto, y que el Derecho internacional de los Derechos Humanos no es en sí aplicable, por lo menos se lo deja de lado, en el contexto de las operaciones militares ${ }^{164}$. Este enfoque está siendo actualmente mitigado por aquellos que piensan que ambos cuerpos jurídicos son complementarios y colindantes, por lo que convendría aplicar la regla más específica y más relevante para tratar mejor el tema. Para otros, sin embargo, aplicar la lex specialis es marginar el Derecho internacional de los Derechos Humanos ${ }^{165}$. Desde esta perspectiva, y al margen de estas consideraciones, no se puede negar que de hecho Israel tiende a aplicar las obligaciones humanitarias y los Derechos Humanos por una vía o por otra, como se ha demostrado en el caso Al-Bassiouni.

Lo que sí que deja claro la Corte es que en relación con Gaza subsiste un conflicto armado, en el que la población civil se encuentra por desgracia en zona de combate, y es esta

\footnotetext{
${ }^{162}$ En efecto, en el párrafo 22 de la sentencia, la Corte va al grano, y no especula ni menciona para nada el enfoque funcional, sino el Derecho internacional humanitario y el de los Derechos Humanos, al señalar lo siguiente: "In conclusion, we reiterate that the Gaza Strip is controlled by a murderous terrorist organization, which acts relentlessly to inflict harm on the State of Israel and its inhabitants, violating every possible rule of international law in its violent acts, which are directly indiscriminately at civilians-men women and children. Despite this, as we said above, the State of Israel is committed to fighting the terrorist organizations within the framework of the law and in accordance with the provisions of international law, and to refrain from international harm to the civilian population in the Gaza Strip. In view of all of the information presented to us with regard to the supply of electricity to the Gaza Strip. we are of the opinion that the amount of industrial diesel that the State said it intends to supply, as well as the electricity that is continually supplied through the power lines from Israel, are capable of satisfying the essential humanitarian needs of the Gaza Strip at the present". Para un mayor desarrollo sobre este caso AlBassiouni y los argumentos de la Corte Suprema de Israel, véase. Rubin, Benjamin.: "Disengagement from the Gaza Strip and Post-Occupation Duties", Israel Law Review (January 2010), pp. 528-563. Este autor recoge los argumentos de la Corte como válidos, e insiste en que a pesar de que Israel no es Potencia Ocupante tras la Desconexión, Israel continúa teniendo ciertas obligaciones y, entre ellas, el suministro de diésel y electricidad a la zona, p. 563.

${ }^{163}$ Es sabido la complementariedad existente entre el Derecho internacional humanitario y el de los Derechos Humanos, por lo que ciertas obligaciones podrían caer indistintamente en ambos ámbitos, que no son excluyentes. A este respecto, Gill, Terry.D.: "Some Thoughts on the Relationship Between International Humanitarian Law and International Human Rights Law: A Plea for Mutual Respect and a Common-Sense Approach”, Yearbook of International Humanitarian Law, 2013, pp. 251-266. Para este autor las controversias doctrinales que se han suscitado en torno a una cierta competencia entre ambos cuerpos jurídicos no tienen sentido: "To me the incessant competition and jockerying for precedence by humanitarian law and human rights lawyers and advocates is unnecessary, incorrect as a matter of law and is dangerously counterproductive. One should recall that that basic purpose of both IHL and IHRL in the context of an armed conflict is to provide the maximum degree of protection possible to persons who are at risk and are vulnerable to abuse, while recognising the extraordinary nature and reality of armed conflict. Whether one likes or not 'war' is a situation which has occurred throughout history and which is likely to continue to occur for the foreseeable future". Ver p. 265.

${ }^{164}$ Sobre este tema, ver más detalles en Ibid, p. 255. Ver también Kleffener, Jann K.: "Human Rights and Humanitarian Law: General Issues", en Gill, Terry D. y Fleck, Dieter. (eds.) (2010): The Handbook of the International Law of Military Operations, Oxford, Oxford University Press, pp. 51-77, especialmente pp. 68-69. ${ }^{165}$ Doswald-Beck, Louise.: Human rights in Times of Conflict and Terrorism, Oxford, Oxford University Press, pp. 2-11 y 112-113.
} 
población la primera y la principal víctima de las hostilidades, a pesar de los esfuerzos que se hacen por limitar los daños. Esta situación también la ha vivido Israel en varias épocas a causa de los atentados terroristas, y en este caso no se trataba de daños colaterales, sino que su intención era atacar directamente a la población civil inocente. Para la Corte, “... This is the difference between de State of Israel, a democratic State fighting for its survival by the means that the law provides, and the terrorist organizations, that seek to destroy it"166.

Hay que reconocer, sin embargo, que lo que se ha denominado en la doctrina como "post-occupation law" es algo que se ha creado y elaborado a partir de otros sectores del Derecho internacional. Pero como ya se ha señalado, esta afirmación requiere dos comentarios: "First, it may be argued that application of norms from other bodies of law to a post-occupation situation may constitute a negative incentive to the termination of occupation. The answer to this two-fold. First, occupation is not illegal in it self. The imperative of post-occupation law should therefore be not the bringing of occupation to an end but the regulation of that end when it occurs. Moreover, applicability of norms from other bodies of law may incentivize the occupant to bring the dependence it self to an end, even it the occupation continues. Secondly, while post-occupation law may draw on existing regimes with respect to discrete issues, pertinent differences must be taken into consideration... In conclusion, the tension between post-occupation law and other regimes indicates the need for a careful delineation of the place of post-occupation law, so as not to undermine its own potential efficacy and that of other regimes"167.

Desde esta perspectiva, la incesante Carrera competencial por ver que cuerpo de normas tiene prioridad, si las del Derecho internacional humanitario o si las del Derecho internacional de los Derechos Humanos no tiene, a nuestro entender, sentido e incluso puede ser incorrecta desde un punto de vista jurídico por no decir peligroso. Lo importante es que se otorgue el máximo de protección a las personas que corren más riesgos y que son más vulnerables, tomando en consideración la naturaleza y la realidad sobre el terreno del conflicto armado. Hay que dejar de lado, pues, las interpretaciones conflictivas e intentar aplicarlas siempre teniendo como objetivo la protección de la víctima. Así las cosas, pretender imponer a Israel determinadas obligaciones para hacer frente al caos que puede reinar en la Franja de Gaza, es en la práctica muy difícil de llevar a cabo no solo por sus propias normas jurídicas como, por ejemplo, el no reconocimiento de la aplicación extraterritorial de los Derechos Humanos, sino por una imposibilidad fáctica, salvo que se vuelva a reocupar la Franja.

\section{Conclusión}

La denominada Desconexión de la Franja de gaza por parte de Israel el 12 de septiembre de 2005 ha traído consigo que Israel ya no pueda ser considerado como Potencia Ocupante, al faltar los elementos esenciales de la ocupación, como se ha apuntado, es decir, el control de facto del territorio bajo autoridad del ejército enemigo, y que esa autoridad esté establecida y en condiciones de ejercerse tal y como está previsto en el Reglamento de La Haya de 1907. Estos son los pilares para determinar si hay o no ocupación, por lo que todas las interpretaciones o posicionamientos que intenten limitar o reinterpretar abusivamente estos pilares solo podría considerarse como de lege ferenda. En efecto, es evidente que esta Desconexión ha conducido a una transferencia efectiva del control de ese territorio a la entonces Autoridad Palestina, y aunque sea difícil de establecer el momento preciso, a nuestro entender es el 12 de septiembre de 2005, esto no es óbice para poder afirmar a todas luces que Israel no es ya desde aquel

\footnotetext{
166 Al-Bassiouni and Others v. Prime Minister..., op, cit., párrafo 21.

167 Ronen, Yaël: “Post-Occupation Law”, en Stahn, Carsten, Easterday Jennifer S., and Iverson Jens (eds.) (2014): Just Post-Bellum: Mapping the Normative Foundations, Oxford, Oxford University Press, pp. 428-446, en especial p. 445.
} 
entonces Potencia Ocupante. Lo que ha ocurrido después en ese territorio, con la llegada al poder de Hamás, es harina de otro costal, aunque esto no quiere decir que no haya complicado la situación de la población de la zona, manteniendo con Israel un conflicto que ha acarreado centenares de muertos y miles de heridos. Desde esta perspectiva, no se puede pretender que Israel esté en condiciones de ejercer y de ejecutar las obligaciones que incumben bajo un régimen de ocupación.

Pero el hecho de que Israel ya no sea Potencia Ocupante, no implica que esté absolutamente liberado de cualquier obligación con ese territorio. Esas obligaciones pueden derivarse de la aplicación del Derecho internacional humanitario o del Derecho internacional de los Derechos Humanos. $\mathrm{Y}$ es que las pretensiones vertidas en torno a una serie de obligaciones denominadas pos-ocupacionales por algunos autores u ONGs distan mucho de ser reconocidas, incluso en los casos de ocupación longa manu. Esto se debe en buena medida a que el régimen jurídico de la ocupación fue previsto para situaciones de corto y medio plazo, pero no para ocupaciones de largo plazo, como es el caso de la Franja de Gaza. De ahí, que se quiera poner remedio a estas lagunas de forma apresurada y sin contar con un mínimo de garantías de seguridad jurídica. Si a esto añadimos los elementos políticos que están siempre presentes a la hora de analizar el conflicto israelo-palestino, es muy fácil caer en una cierta parcialidad o, incluso, arbitrariedad. Que haya que completar o desarrollar el régimen de Ocupación, el que suscribe estas líneas no lo pone en duda, pero esto no implica que sea conveniente aplicar un Derecho que no existe, al menos a día de hoy.

\section{Bibliografía}

Abi-Saab, Rosemary : “Conséquences juridiques de l'édification d'un mur dans le territoire palestinien occupé. Quelques réflexions péliminaires sur l'avis consultatif de la Cour internationale de Justice", RICR (2004), pp. 633-657.

Agha, Hussein y Malley, Robert H..: "Elecciones de alto riesgo en Oriente Próximo", Le Monde Diplomatique, edición española, enero 2006.

Alvarez-Ossorio, Ignacio.; Levy, Gideo.; Bishara, Marwan.; Hadas Samuel y Harel, Victor, en la revista Política Exterior, vol. 20, nº 110 (marzo/abril 2006), pp. 33-68.

Arai-Takashi, Yutuka:: The Law of Ocupation: Continuity and Change of International Humanitarian Law, and its Interactions with International Human Rights, Nijhoff, Leiden, 2009, $760 \mathrm{p}$.

Azarova, Valentina.: “Disingenuous 'Disengagement': “Israel's Occupation of the Gaza Strip and the Protective Function of the Law of Belligerent Occupation". Symposium on the Functional Approach to the Law of Occupation. Opinio iuris, April 2012, en http://opiniojuris.org/2012/04/23/symposium-on-the-functional-approach-to-the-lawofoccupation.

Baker, Alan : "Le droit international humanitaire, le CICR et le statut d'Israël dans les territoires", Revue internationale de la Croix-Rouge (2012) pp. 333-343.

Ben- Ami, Slomo: Cicatrices de guerra, heridas de paz: la tragedia árabe-israelí, Ediciones B. Barcelona, 2006.

Ben-Naftali, Oma y Shany, Yuval.: "Living in Denial: The Application of Human Rights in the Occupied Territories", Israel Law Review (2003-2004), pp. 17-118. 
"Belligerant Occupation: a Plea for the establishment of an International Supervisory Body Mechanism", en: Cassesse, Antonio (ed.) (2012): Realizing Utopia: the Future of International Law, Oxford University Press, Oxford, pp. 538-551.

Benvenisti, Eyal: "Responsibility for the Protection of Human Rights under the Israeli Palestinians Agreements", Israel Law Review, 1994, pp. 297-377.

--Water Conflict During the Occupation of Iraq", AJIL, vol.. 97, nº 4 (October 2003),

-- (2012): The International Law of Occupation, Oxford University Press, Oxford, $2^{\mathrm{a}}$ ed.

Bermejo García, Romualdo. y Pozo Serrano, Pilar (2011).: Una tierra, dos Estados: Análisis jurídico-político del conflicto árabe-isralí, Pamplona, Eunsa.

Bermejo García, Romualdo (2002).: El conflicto árabe-israelí en la encrucijada: ¿Es posible la paz?, Eunsa.

--"La guerra de Irak y el Derecho Internacional humanitario (DIH)", en: Ramón Chornet, Consuleo (ed.) (2005): Derechos y libertades ante las nuevas amenazas a la seguridad global”, Tirant Lo Blanch.

-- "La protección de la población civil en Libia como coartada para derrocar un gobierno: un mal inicio para la responsabilidad de proteger", AEDI, 2011.

-- "La valla de seguridad contra el terrorismo palestino a la luz de la Sentencia de la Corte Suprema de Justicia israelí de 30 de junio de 2004", REDI, 2004; ídem "Israel y la valla de seguridad contra el terrorismo palestino", en Soberanía del Estado y Derecho internacional. Homenaje al Prof. Juan Antonio Carrillo Salcedo, Universidad de Córdoba, Sevilla y Málaga, Sevilla, 2005.

-- "Comentarios en torno a la Opinión Consultiva de la Corte Internacional de Justicia sobre el mal denominado 'muro' de Israel contra el terrorismo palestino: una Opinión muy 'opinable"”, en Ramón Chornet, Consuelo (coord.) (2006): Uso de la fuerza y protección de los derechos humanos en un nuevo orden internacional, Tirant lo Blanc, Valencia.

Bianchi, Andrea.: "Dismanthing the Wall: The ICJ's Advisory Opinion and its likely Impact on International Law", GYIL, 2004.

Bockel, Alain : "Le retrait israélien de Gaza et ses conséquences sur le droit international », AFDI, 2005.

Bubinsky, A.: "La desconexión le puede costar el puesto a Sharon", Línea Directa con Israel y Medio Oriente, septiembre de 2005.

Cervell Hortal, María José: “La Resolución 1970 (2011) del Consejo de Seguridad y la remisión de la cuestión libia a la CPI: ¿la unión hace la fuerza?”, AEDI, 2011.

Chetail, Vicent (ed. (2013) : Permanence et mutations du droit des conflits armés, Bruylant, Bruselas.

Condorellli, Luigi. y Boisson de Chazournes, Laurence.: "Quelques remarques à propos de l'obligation des Etats à respecter et faire respecter le droit international humanitaire en troutes circonstances", en: Etudes et essais sur le droit international humanitaire et sur les príncipes de la Croix-Rouge, Mélanges en l'honneur de J. Pictet, (1984) Nijhoff, La Haye.

Cuyckens, Hanne: “The law of Occupation”, en Wouters, Jan. De Man, Philip., Verlinden, Nele (eds) (2016): Armed Conflicts and the Law Intersentia Antwert, Intersentia, Antwerp.

Cock, Chris (2011): "Operation Unified Protector and the Protection of Civilians in Libia", Yearbook of International Humanitarian Law. 
Deshowitz, Alan (2009): The Case Against Goldstone Report: A Study in Evidentiary Bias, Harvard Library, $50 \mathrm{p}$.

Dinstein, Yoram.: The International Law of Belligenent Occupation, Cambridge University Press, Cambridge, 2009.

Dörmann, Kunt. y Colassis, Laurent.: "International Humanitarian Law in the Irak Conflict", GYIL (2004).

Doswald-Beck, Louise (2011): Human rights in Times of Conflict and Terrorism, Oxford, Oxford University Press. 733 p.

Dugard, John : Rapport sur la situation des droits de l'homme dans les territoires palestiniens occupés, Rapporteur special, E/CN.4/2006/29 de 17 janvier 2006.

Echeverría Jesús, Carlos: "Revueltas, guerra civil tribal e intervención militar extranjera en Libia", AEDI, 2011, pp. 85-201.

Ferraro, Tristian.: "Determining the Beginning and End of an Occupation under International Humanitarian Law", Int. Rev. Red. Cross (2012), pp. 133-163.

Gaggioli, Gloria. y Kolb, Robert (eds.) (2014): Research Handbook on Human Rights and Humanitarian Law. Edward Elgar, Cheltenham, 704 p..

Gill, Terry.D. y Fleck, Dieter. (eds.) (2010): The Handbook of the International Law of Military Operations, Oxford, Oxford University Press, 728 p.

Fox, Gregory. H.:" Eyal Benvenisti. The International Law of occupation", European Journal of International Law, vol. 24, no 1 (February 2013).

Ghelali, Anna : "Lex specialis, droit international humanitaire et droits de l'homme: leur interaction dans les nouveaux conflits armés", RGDIP (2007), pp. 539-574.

Gill, Terry.D.: "Some Thoughts on the Relationship Between International Humanitarian Law and International Human Rights Law: A Plea for Mutual Respect and a Common-Sense Approach", Yearbook of International Humanitarian Law, 2013, pp. 251-266.

Good, Davis P.: “The Need for Fundamental Change in the Law of Belligerent Occupation", Standford Law Review (1985), pp. 1573-1608.

Greenwood, Christopher.: "The Administration of Occupied Territory in International Law", en Playfair, Emma (ed.) (1992): International Law and the Administration of Occupied Territories, Clarendon Press, Oxford, pp. 250-265.

International Humanitarian Law and the Challenges of Contemporaryu Armed Conflicts, Report prepared by the International Commettee of the Red Cross, Geneva, 31nd International Conference of the Red Cross and Red Crescent, octubre 2011.

International Humanitarian Law and the Challenges of Contemporary Armed Conflicts, preparado por el CICR en la $32^{\mathrm{a}}$ International Conference of the Red Cross and Red Crescent, Geneva, 8-10 diciembre 2015.

Gresh, Alain.: "Intifada para una verdadera paz", Le Monde Diplomatique, diciembre, 2000, pp. 10-11.

Gutiérrez Espada, Cesáreo.: “Sobre el 'núcleo duro' de la Resolución 1973 (2011) del Consejo de Seguridad y acerca de su aplicación práctica”, AEDI, 2011, pp. 57-75.

Haggenmacher, Peter : 'L'occupation militaire en droit international : Genèse et profil d'une institution juridique", Relations Internationales (1994), pp. 285-301. 
Haupais, Nicolas : "Les obligations de la Puissance occupante au regard de la jurispradence et de la pratique recentes", RGDIP (2007), pp. 117-146.

Hove, Matthew R.: "The Occupation of Irak: A Military Perspective on Lessons Lerned", Int.Rev. Red. Cross (2012), pp. 339-346.

--“The End of Occupation: Irak 2004”, International and Comparative Law Quarterly (2005).

Kleffener, Jann K.: "Human Rights and Humanitarian Law: General Issues", en Gill, Terry.D. y Fleck, Dieter. (eds.) (2010): The Handbook of the International Law of Military Operations, Oxford University Press, pp. 51-77.

Kolb, Robert y Vité, Silvain.: "L'applicabilité ratione temporis du droit de l'occupation de guerre: le debut et la fin de l'occupation”, en Chetail, Vicent. (ed.) (2013) : Permanence et mutations du droit des conflits armés, Bruylant, Bruselas, pp. 97-148.

-- (2009) : Le droit de l'ocupation militaire. Perspectives historiques et enjeux juridiques actuels, Bruylant, Bruselas, $482 \mathrm{p}$.

Koutroulis, Vaios.: "The Application of International Humanitarian Law and International Human Rights in Situation of Prolonged Occupation: Only a Matter of Time?", Int. Rev. Red.Cross (2012), pp. 165-205.

-- (2010) : Le debut et la fin de l'application du droit de l'occupation, Pedone, París, 334 p.

Kretzmer, David: "The Supreme Court of Israel: Judicial Review during Armed Conflict", GYIL (2004), pp. 792-456.

--"The Law of Belligerent Occupation in the Supreme Court of Israel”, Int. Rew. Red. Cross (2012), pp. 207-236.

Luft, Michal.: "Living in a Legal Vacuum: the Case of Israel's Legal Possition and Policy Towards Gaza Residents", Israel Law Review (2018), pp. 193-234.

López-Jacoiste Díaz, María Eugenia.: "Algunas reflexiones sobre la Opinión Consultiva sobre el muro: la solución está en Ramalla y Gaza y no en La Haya o Manhattan", Anuario de Derecho Internacional, 2004, pp. 467-491.

-- "La crisis de Libia desde la perspectiva de la responsabilidad de proteger". "Cuestiones en torno a la legitimidad del Consejo Nacional de Transición Libio a raíz de su reconocimiento por la Asamblea General de las Naciones Unidas”, AEDI (2011), pp. 109-152.

Lubell, Noam: "Human Rights Obligations in Military Occupation", Int. Rev. Red. Cross (2012), pp. 317-337.

Maurer, Peter : "Obstacles au droit international humanitaire: la politique israélienne d'occupation", Revue internationale de la Croix-Rouge (2012), pp. 323-331. Este artículo está publicado íntegramente en inglés con el título "Challenges to International Humanitarian Law: Israel's to Occupation Policy", Int. Tev. Red. Cross., no 4 (2012), pp. 1503-1511.

--“War in Cities: What is at Stake?", Int. Rev. of the Red Cross (2016), pp. 639-646.

Milanovic, Marco.: "European Court Decides that Israel is not Occupping Gaza", EJIL Talk! 17 june 2015.

Momtaz, Djamchid.: "Israel and the Fourth Geneva Conventions: On the ICJ Advisory Opinion Concerning the Separation Barrier", Yearbook of International Humanitarian Law, 2005, pp. 213-235 
Morris, Benny (2001): Righteaus Victims. A History of the Zionist-Arab conflict 1881-2001, Random House, 768 p.

Mouton, Jean-Denis: 'L'autonomie palestinienne àprès l'accorá intérimaire israelo-palestinien du 28 septembre 1995: originalité, ambiguïté, tensión”, RGDIP (1996), pp. 951-978.

Paust, Jordan J.: "The U.S. as Occuping Power Over Portions of Irak and Relevant Responsibilities Under the Laws of the War", ASIL, vol. 8, (April 2003) en http://www.asil.org/insights/insight102.htm;.

Pozo Serrano, Pilar.: "La Opinión Consultiva de la CIJ sobre las consecuencias jurídicas de la construcción del muro en el territorio ocupado palestino: problemas de competencia y oportunidad judicial”, Anuario de Derecho Internacional, 2004, pp. 493-518.

Quand, William B.: Peace Process. American Diplomacy and the Arab-Israeli Conflict since 1967, $3^{\text {a }}$ Edition, Brooking Institution Press, Washington D.C., 2005, 535 p.

Raguan, Galit: “Adjudicating Armed Conflict in Domestic Courts: The Experience of Israel's Supreme Court", Yearbook of International Humanitarian Law, 2010, pp. 61-95.

Redalié, Lorenzo.: La conduite des hostilités dans les conflits armés asymétriques: un défi au droit humanitaire, LGDJ/Schulthess/Collection Genevoise, Ginebra/Zurich/Basilea, 23 mars 2013, 378 p.

Rivier, Raphaële : "Conséquences juridiques de l'édification d'un mur dans le territoire palestinien occupé. Cour internacionale de Justice. Avis consultatif du 9 juillet 2004", AFDI (2004), pp. 292-336.

Roberts, Adam.: "Prolonged Military Occupation: the israelí-occupied territories since 1967", AJIL (1990), pp. 44-103.

--" Decline of illusions. The Status of the Israeli-occupied Territories avec 21 Years", International Affairs, vol. 64 (1988), pp. 345-359.

--“The End of Occupation: Irak 2004”, International and Comparative Law Quarterly (2005), pp. 27-48.

--“What is Military Occupation?”, BYIL (1984), pp. 249-305.

Ronen, Yaël: "Post-Occupation Law", en Stahn, Carsten, Easterday Jennifer S., and Iverson Jens (eds.) (2014): Just Post-Bellum: Mapping the Normative Foundations, Oxford, Oxford University Press, pp. 428-446.

Rubin, Benjamin.: "Disengagement from the Gaza Strip and Post-Occupation Duties", Israel Law Review (January 2010), pp. 528-563.

Scheffer, David.J.: “Beyond Occupation Law”, AJIL (2003), pp. 842-860.

Schlonimsky, I.: "Con las piedras, con la prensa y con la red. Sin guerra, pero luchando por todos los frentes", Línea Directa con Israel y Medio Oriente, 11 de noviembre 2000, pp. 2426.

Shanny, Yuval: "Faraway, so close: The Legal Status of Gaza after Israel's Disengagement", Yearbook of International Humanitarian Law (2005), p. 382.

--“Binary Law Meets Complex Reality: The Occupation of Gaza Debate”, Israel Law Review (2008), pp. 68-86.

--The Law Applicable to Non-occupied Gaza: A Comment on Bassiouni, V.: "The Prime Minister of Israel", Israel Law Review (2008), pp. 68-86. 
Shawan, Jabarin : "Le territoire palestinien occupé et le droit international humanitaire. Réponse à Peter Maurer", Revue internationale de la Croix-Rouge (2013), pp. 161-174.

Starita, Massimo : "L'occupation de l'Irak, le Conseil de sécurité, le droit de la guerre et le droit des peuples à disposer d'eux mêmes", RGDIP, (2004), pp. 884-916.

Stephanopoulos Nicholas.: "Israel's Law Obligations to Gaza After the Pullout", Yale Journal of International Law (2006), pp. 524-528.

-- (2004): The of the Law of Armed Conflict, Oxford, Oxford University Press.

Thürer, Daniel y McLaren, Malcom: "Just Post Bellum, in Irak: A Challenge to the Applicability and Relevance of International Humanitarian Law", en Dinke Klaus et alia (2005): Weltinnenrecht, Liber Amicorum Jost Delbiück, Berlín, Duncker, and Humblod

Tigroudja, Hélène : “Le régime d'occupation d'Irak", AFDI (2004), pp. 77-101.

Venet, Olivia : “L'occupation du territoire irakien et l'intervention du Conseil de sécurité: conséquences sur les pouvoirs reglementaires de la puissance ocupante et réflexions sur les modes d'action choisies", RBDI (2006), pp. 274-299.

Veuthey Michel (1983) : "Guérrilla et droit humanitaire”, CICR.

Vité, Sylvain : “Typologie des conflits armés en Droit international humanitaire : concepts juridiques et politiques", especialmente, pp. 12-13, en relación con la Franja de Gaza. Este estudio se ha publicado en inglés con el título "Typologie of Armed Conflicts in International Humanitarian Law: Legal Concepts and Actual Situations", Int. Rev. Red. Cross (2009), pp. 6994, especialmente, pp. 83-85 en relación con Israel.

Watson, Geoffrey R. (2000): The Oslo Accord: International Law and the Israeli-Palestinian Preace Agreements, New York Oxford University Press. 